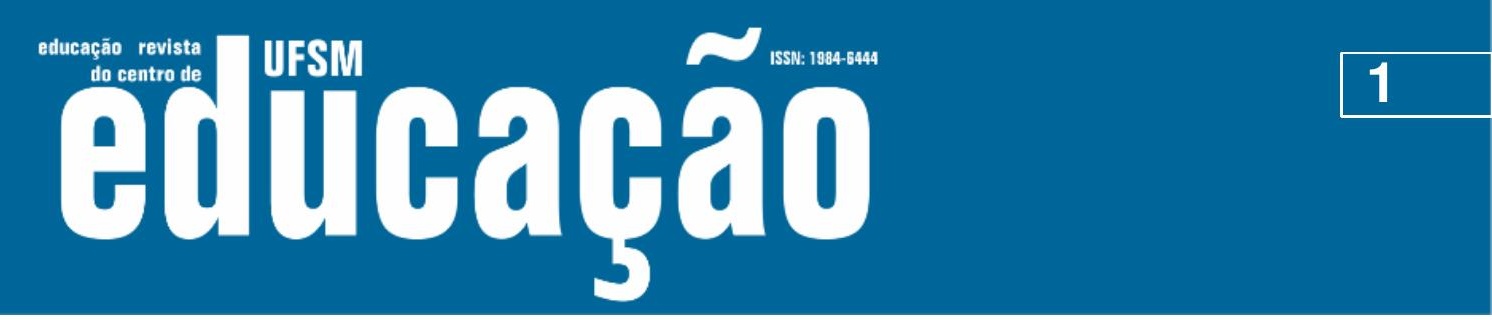

ISSN: 1984-6444 | http://dx.doi.org/10.5902/1984644432632

\title{
Como docentes da UFRN abordaram o tema deficiência em pesquisa e extensão dez anos antes das cotas?
}

\author{
How do UFRN teachers approached the disability theme in research and \\ extension ten years before quotas?
}

\author{
Bruno Santana da Silva \\ Universidade Federal do Rio Grande do Norte \\ Adja Ferreira de Andrade \\ Universidade Federal do Rio Grande do Norte
}

Recebido em 15 de maio de 2018

Aprovado em 21 de fevereiro de 2019

\section{RESUMO}

Os resultados dos movimentos sociais para a inclusão de pessoas com deficiência na sociedade chegaram à educação superior. As instituições federais de ensino superior (IFES) passam por um grande marco com modificações na lei de cotas, que a partir da seleção anual de 2018 reserva vagas para as pessoas com deficiência. As barreiras atitudinais dos docentes são um dos principais desafios que estes discentes vão enfrentar nas IFES, pois trazem impactos pedagógicos e administrativos. A continuidade da inclusão de pessoas com deficiência no ensino superior precisa buscar maneiras de eliminar as barreiras atitudinais dos docentes. Neste contexto, é relevante investigar experiências bem-sucedidas de IFES para orientar 0 enfrentamento destas barreiras. Este trabalho teve como objetivo compreender como a cultura de inclusão evoluiu na Universidade Federal do Rio Grande do Norte nos dez anos antes da lei de cotas (2008-2017), sob a perspectiva da participação docente em projetos de pesquisa e extensão relacionados com o tema deficiência. Foi realizado um estudo descritivo documental de todos projetos registrados no sistema computacional de gestão acadêmica da universidade. Colaboração entre docentes e interdisciplinaridade foram as principais características da evolução dos projetos de pesquisa e de extensão relacionados com o tema deficiência na universidade. Estas características parecem ter tido papel importante na eliminação de barreiras atitudinais e na disseminação da cultura de inclusão em pesquisa e extensão. Como consequência, quase todos os centros se envolveram com estes projetos, com uma grande variedade de temas e deficiências abordadas.

Palavras-chave: Deficiência; Barreira atitudinal; Pesquisa; Extensão.

\section{ABSTRACT}

Results of social movements for people with disabilities inclusion in society have reached college education. Federal higher education institutions (FHEI) go through a major milestone with modifications in the quotas law, which from the annual selection of 2018 reserves vacancies for people with disabilities. Teacher's attitudinal barriers are one of main challenges these students will face in $\mathrm{FHEI}$, as they have pedagogical and administrative impacts. Continuing the inclusion of people with disabilities in higher education needs to find ways to eliminate teacher's attitudinal barriers. In this context, 


\section{DF HEM Eulloahá}

ISSN: 1984-6444 | http://dx.doi.org/10.5902/1984644432632

it is important to investigate successful experiences of $\mathrm{FHEl}$ to address these barriers. This work aimed to understand how the inclusion culture evolved at Federal University of Rio Grande do Norte in ten years before the quota law (2008-2017), from the perspective of teacher participation in research and extension projects related to the disability theme. A documental descriptive study was carry out on all projects registered in the academic computer system of the university. Collaboration among teachers and interdisciplinarity were the main characteristics of the evolution of research and extension projects related to the disability theme at the university. These characteristics seems to have played an important role in elimination of attitudinal barriers and in dissemination of inclusion culture in research and extension. As a consequence, almost all centers have been involved in these projects, with a wide variety of addressed themes and disabilities.

Keywords: Disability; Attitudinal barrier; Research; Extension.

\section{Introdução}

A responsabilidade de participação das pessoas na sociedade recaía apenas sobre cada sujeito. Quem possuía alguma deficiência era responsável por superar barreiras que o impediam de participar da convivência social. Os movimentos sociais recentes reivindicam um novo modelo de inclusão de pessoas com deficiência. Buscase compreender a sociedade com maior diversidade e as deficiências passam a ser consideradas diferenças naturais entre as pessoas. Desse modo, as pessoas com deficiência começam a ser tratadas como as demais pessoas na sociedade, sem discriminação, sem serem marginalizadas e valorizando suas capacidades para a participação efetiva na sociedade.

Esses movimentos sociais vêm disseminando ações sistêmicas de inclusão nas diversas atividades humanas. Um ponto de partida importante tem sido a criação de políticas que garantam direitos iguais para todas as pessoas, incluindo as pessoas com deficiência. O Brasil ratificou a Convenção sobre os Direitos das Pessoas com Deficiência da Organização das Nações Unidas (Brasil, 2008), que aborda temas como educação, saúde, trabalho, transporte, cultura, esporte e lazer. Em torno desta convenção, uma série de outras leis vem reforçando os direitos das pessoas com deficiência até culminar recentemente na Lei Brasileira de Inclusão da Pessoa com Deficiência (Brasil, 2015).

Esta lei consolida a garantia da inclusão de pessoas com deficiência em todos os níveis de ensino. Elas devem ter acesso a condições necessárias para 


\section{Autตaดูão}

ISSN: 1984-6444 | http://dx.doi.org/10.5902/1984644432632

desenvolverem suas capacidades, respeitando seus interesses e características. Acesso, permanência e participação de pessoas com deficiência em ambientes educacionais é resultado de um compromisso coletivo do Estado, instituições de ensino, família e sociedade.

O movimento de inclusão na Educação progrediu pelos níveis de ensino, do fundamental até o superior. As instituições federais de ensino superior (IFES) também se envolveram. Um dos primeiros estímulos do Estado foi a criação dos núcleos de acessibilidade nas IFES (Brasil, 2011). Essas políticas continuam evoluindo e criaram recentemente cotas para pessoas com deficiência no ingresso em cursos ofertados pelas IFES (Brasil, 2016). Após um período de regulamentação, em 2018 houve a primeira seleção anual com as cotas para pessoas com deficiência. Este é um importante marco para as IFES, pois modificará o perfil do corpo discente ingressante.

Discentes com deficiência têm encontrado várias barreiras que limitam ou impedem sua participação nas atividades das IFES: urbanísticas, arquitetônicas, informacionais, comunicacionais, tecnológicas e atitudinais. Como os docentes são responsáveis pelas atividades pedagógicas e, na maioria das vezes, também pela coordenação das atividades administrativas nas IFES, a barreira atitudinal imposta pelos docentes tem um forte impacto na inclusão e permanência de discentes com deficiência no ensino superior. Não é raro encontrar docentes que ignoram a existência dos discentes com deficiência na IFES, ou aqueles que consideram os discentes com deficiência como incapazes de aprender e desenvolver suas habilidades, segundo o modelo de déficit (Ainscow,1995). Os docentes tendem a se concentrar tanto nas limitações das pessoas com deficiência que se esquecem que elas também possuem capacidades a serem desenvolvidas, com potencial produtivo relevante. Um dos grandes desafios para a inclusão no ensino superior é a necessidade de uma mudança na cultura dos docentes; seja pela a crença equivocada sobre a inferioridade dos discentes com deficiência, seja pela necessidade de mudar suas práticas pedagógicas (isto é, seus hábitos no trabalho) para investir no desenvolvimento das potencialidades dos discentes.

Essa barreira atitudinal dos docentes pode ter sido consequência de vários fatores ao longo da sua vida pessoal, educacional e profissional. A maioria dos 


\section{F HEM etituará

ISSN: 1984-6444 | http://dx.doi.org/10.5902/1984644432632

docentes do ensino superior (1) não conviveu com pessoas com deficiência, (2) não conhece as limitações impostas pelas diversas deficiências e as capacidades a serem desenvolvidas que não foram afetadas pelas deficiências, (3) não possui formação pedagógica típica das licenciaturas e (4) desconhece materiais didáticos e práticas pedagógicas adaptados para a diversidade de discentes com deficiência. A inclusão de discentes com deficiência nas IFES precisa envolver formas de eliminar as barreiras atitudinais dos docentes.

Torna-se relevante investigar experiências de IFES que estão evoluindo no processo de inclusão de pessoas com deficiência no seu corpo discente. Uma melhor compreensão dessas experiências pode apontar possíveis caminhos a serem explorados na remoção de barreiras atitudinais dos docentes. A remoção das barreiras é fundamental para que as IFES lidem adequadamente com a nova realidade do corpo discente a partir da lei de cotas (Brasil, 2016). A Universidade Federal do Rio Grande do Norte (UFRN) tem apresentado bons resultados na inclusão de pessoas com deficiência. Suas experiências de inclusão merecem ser investigadas, compartilhadas e discutidas.

Neste contexto, esta pesquisa teve como objetivo analisar como os docentes da UFRN abordaram o tema deficiência em projetos de pesquisa e de extensão durante dez anos antes da lei de cotas, entre 2008 e 2017 (Brasil, 2016). Foi possível traçar um panorama do envolvimento dos docentes da universidade com o tema deficiência em atividades extraclasse. Esse envolvimento docente tende a eliminar barreiras atitudinais quando eles receberem discentes com essas características nas suas turmas. Deste modo, essa compreensão sobre os docentes é um importante subsídio para identificar estratégias e oportunidades para continuar o processo de remoção das barreiras atitudinais dos docentes nesta e em outras IFES.

A próxima seção discute alguns trabalhos relacionados. Depois, apresenta-se o contexto da UFRN no período analisado. Relata-se, então, a pesquisa realizada em termos de objetivos, metodologia, discentes, projetos de pesquisa, projetos de extensão e discussão. Conclui-se com as considerações finais. 


\section{F HWM Eutinará

ISSN: 1984-6444 | http://dx.doi.org/10.5902/1984644432632

\section{Inclusão de pessoas com deficiência no ensino superior}

Trabalhos anteriores investigaram a inclusão de pessoas com deficiência no ensino superior, em particular, considerando ingresso e permanência. Alguns analisaram de maneira geral as iniciativas (Duarte et al., 2013; Castro e Almeida, 2014). Outros concentraram-se na atuação dos núcleos de acessibilidade das IFES (Saraiva, 2015; Ciantelli e Leite, 2016), nos currículos (Magalhães, 2013), na formação continuada da comunidade acadêmica (Mantoan e Baranauskas, 2009) e na produção de materiais didáticos (Salton et al., 2017).

A UFRN também foi objeto desses estudos. Albino (2010), Melo e Rildeci (2007) e Ferreira (2016) investigaram acesso e permanência de discentes com deficiência nesta universidade. Martins (2016) investigou práticas e formação dos docentes neste processo de inclusão. Severino (2017) avaliou a implementação do Programa Incluir na UFRN.

Poucos trabalhos investigaram as barreiras atitudinais dos docentes sobre a inclusão de pessoas com deficiência no ensino superior. Chahini (2010) investigou as atitudes sociais e opiniões dos docentes da Universidade Federal do Maranhão através de questionários. Ela concluiu que apesar de os docentes serem relativamente favoráveis ao discurso de inclusão, eles demonstraram atitudes e opiniões mais desfavoráveis em aspectos operacionais. Alencar (2013) entrevistou docentes e discentes da Universidade Federal de Juiz de Fora sobre a inclusão nesta universidade. Concluiu que as barreiras atitudinais são as que demoram mais tempo para serem superadas. Como solução, sugeriu abordar a inclusão nos cursos de graduação e promover eventos de conscientização. Pesquisas sobre barreiras atitudinais geralmente consideram o discurso de algumas pessoas, sem analisar suas práticas. Costumam privilegiar profundidade ao invés de abrangência.

A pesquisa apresentada neste trabalho segue por um caminho diferente. Toma como base a participação em projetos de pesquisa e extensão como indicador real (não intenção em discurso) de atitudes dos docentes envolvidos com a inclusão de pessoas com deficiência. Além disso, considerou-se projetos de todos os docentes da universidade durante dez anos, diferente de registros pontuais em questionários e 


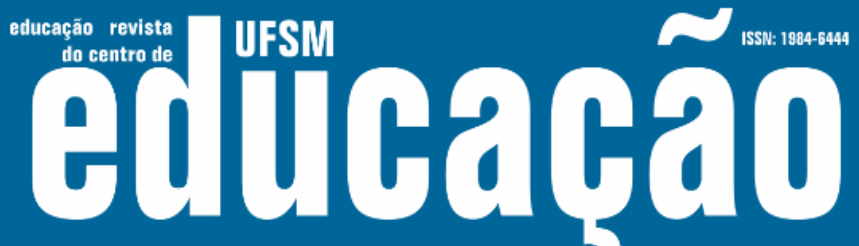

ISSN: 1984-6444 | http://dx.doi.org/10.5902/1984644432632

entrevistas de alguns docentes. Esta opção pela abrangência complementa outros trabalhos que optaram pela profundidade.

\section{Realidade da UFRN dez anos antes das cotas (2008-2017)}

A UFRN desenvolve ações para inclusão desde 2000. O vestibular ofereceu mecanismos adequados para que pessoas com deficiência participassem das seleções de ingresso entre 2000 até 2013, quando foi encerrado para dar lugar apenas ao ENEM/SISU. Comissões que tratam da inclusão têm sido instituídas desde 2002. A universidade tem participado de vários projetos institucionais financiados pelo MEC desde 2004, em especial pelo Programa Incluir. Em 2010, a UFRN criou seu núcleo de acessibilidade (Brasil, 2011) chamado CAENE, Comissão Permanente de Apoio a Estudantes com Necessidades Educacionais Especiais. Ela orienta e apoia a inclusão de discentes com deficiências e outras necessidades educacionais especiais na universidade. Os principais serviços oferecidos são preparo e adaptação de materiais para discentes com deficiência visual, interpretação em Libras de aulas e eventos para discentes surdos, cursos de Libras e outros aspectos de acessibilidade para a comunidade acadêmica em geral. Outra iniciativa importante foi a criação do curso "Letras - Língua Portuguesa e Libras" em 2013. Iniciativas institucionais como essas refletem o empenho da UFRN em oferecer um ambiente educacional adequado para discentes com deficiência.

\section{Participação de docentes da UFRN em projetos de pesquisa e extensão relacionados com deficiência dez anos antes das cotas (2008-2017)}

Esta pesquisa investigou como os docentes da UFRN abordaram em projetos de pesquisa e extensão o tema deficiência durante dez anos antes da lei de cotas (2008-2017). Identificou-se o número de discentes com deficiência que a universidade recebeu neste período para refletir sobre sua influência nos projetos de pesquisa e extensão realizados. Analisou-se o envolvimento dos docentes com temas 


\section{HEM olturaná

ISSN: 1984-6444 | http://dx.doi.org/10.5902/1984644432632

relacionados à deficiência: Quantos docentes realizaram projetos de pesquisa e de extensão que tratavam explicitamente do tema deficiência? Eles pertencem a quais centros? Na capital ou interior? São docentes antigos (com mais de 10 anos) na universidade ou ingressaram recentemente? Quando os docentes começaram a participar de projetos que abordam o tema deficiência? Como ocorreu a colaboração entre docentes nestes projetos? Quais deficiências e temas foram abordadas nestes projetos? As respostas para essas perguntas permitem traçar um panorama do envolvimento dos docentes da universidade com o tema deficiência; configurando-se um importante subsídio para lidar com a nova realidade do corpo discente a partir da lei de cotas.

\section{Metodologia}

Esta pesquisa realizou um estudo descritivo documental (Gil, 2008) com dados disponíveis em meio digital através dos sistemas computacionais de gestão da UFRN, e não dados obtidos diretamente das pessoas em meios físicos. Sob a orientação das questões de pesquisa, realizou-se as seguintes atividades: (1) identificação dos discentes com deficiência que a universidade recebeu entre 2008 e 2017; (2) identificação dos projetos de pesquisa e de extensão que abordaram explicitamente 0 tema deficiência entre 2008 e 2017; (3) análise do título, resumo e palavras-chave de cada projeto para classificá-lo quanto à deficiência e ao tema abordados; (4) identificação dos docentes que participaram em cada projeto; e (5) análise e discussão dos dados coletados. Apenas os docentes que permaneceram na instituição no início de 2018 foram considerados. Estes vão enfrentar a nova realidade discente depois da lei de cotas.

As deficiências consideradas foram: visual, auditiva, motora, intelectual, autismo e de aprendizagem. Elas incluíram graus de limitação mais severos, como a cegueira e a surdez, e graus mais brandos, como a baixa visão e a perda auditiva. Classificou-se como autismo a Síndrome de Asperger e os demais transtornos do espectro do autismo. Deficiências de aprendizagem envolvem transtornos específicos de aprendizagem, transtorno do déficit de atenção ou hiperatividade, dislexia, 


\section{F WEM Gutirahá}

ISSN: 1984-6444 | http://dx.doi.org/10.5902/1984644432632

disortografia, disgrafia ou discalculia. Mesmo não fazendo parte da lei de cotas, elas foram mantidas aqui porque também recebem apoio da CAENE. Não foram consideradas deficiências decorrentes de doenças degenerativas normalmente associadas ao envelhecimento, como Parkinson e Alzheimer, e doenças pouco conhecidas, como Zika, por não serem significativas no corpo discente da UFRN.

A lista de alunos com deficiência foi obtida diretamente da Superintendência de Informática da UFRN, por não ser um dado público. Ela reflete a verificação cuidadosa da deficiência realizada pela CAENE. Realizaram-se apenas agrupamentos de subcategorias conforme a classificação anterior (e.g. baixa visão e cegueira para deficiência visual).

Os dados sobre professores, projetos de pesquisa e de extensão ${ }^{1}$ foram obtidos através do Portal de Dados Abertos (http://dados.ufrn.br) e da parte pública do SIGAA (http://www.sigaa.ufrn.br), Sistema Integrado de Gestão de Atividades Acadêmicas da UFRN. Projetos de pesquisa e de extensão não possuem categorização explícita das deficiências abordadas. Esta categorização foi realizada conforme a interpretação dos pesquisadores a partir da leitura dos títulos, resumos e palavras-chave. Inicialmente buscou-se identificar palavras como acessibilidade, inclusão, deficiência e tecnologias assistivas. Aos poucos foram sendo descobertas palavras relacionadas que passaram a ser consideradas, tais como Libras, Braille e prótese. Alguns projetos abordaram uma ou mais deficiências específicas. Outros, no entanto, abordaram as deficiências de forma geral e foram classificados por em geral.

Os projetos abordaram aspectos distintos das deficiências e dos sujeitos envolvidos. Deste modo, eles também foram classificados quanto ao tema abordado. Cada projeto foi associado a um ou mais temas dependendo da sua atuação. Os temas foram:

\section{Sobre serviços prestados aos deficientes}

- prevenção: cuidados para evitar perdas de capacidades;

- diagnóstico: diagnóstico (precoce) da deficiência;

\footnotetext{
${ }^{1}$ O termo "projeto de extensão" foi utilizado aqui para representar qualquer atividade de extensão como projetos, eventos, produtos ou programas de extensão.
} 


\section{N-T

ISSN: 1984-6444 | http://dx.doi.org/10.5902/1984644432632

- tratamento: atendimento clínico ou terapêutico de deficientes;

- cultura: oferta de serviços culturais acessíveis;

- físico: promoção de atividades físicas para deficientes;

- nutrição: nutrição de deficientes;

- avaliação: verificação de acessibilidade de ambientes e artefatos

- desenvolvimento: desenvolvimento de software acessível

Sobre tecnologias

- tec-assistiva: desenvolvimento de tecnologias assistivas;

- tec-diag: desenvolvimento de tecnologias para diagnóstico de deficiências;

- tec-trat: desenvolvimento de tecnologias para tratamento de deficiências;

- prótese: desenvolvimento de próteses ou órteses para deficiência motora, exceto próteses odontológicas;

Sobre educação

- educação: educação para o próprio deficiente;

- comunidade: educação para pessoas que convivem com deficientes;

- professores: formação de professores (ou semelhantes);

- serviço: formação de prestadores de serviço para deficientes;

- materiais: produção de materiais didáticos para deficientes;

Sobre cidadania

- conscientização: conscientização da sociedade sobre inclusão;

- direito: direitos e políticas para pessoas com deficiência;

- trabalho: promoção do trabalho ou atividades produtivas para deficientes;

- transporte: transporte de deficientes;

Sobre pessoa com deficiência

- deficiência: compreensão da deficiência e das barreiras vivenciadas;

- sujeito: compreensão da identidade, cultura, condição socioeconômica, discurso, dentre outras características do sujeito com deficiência; e

- sexo: sexualidade do deficiente. 


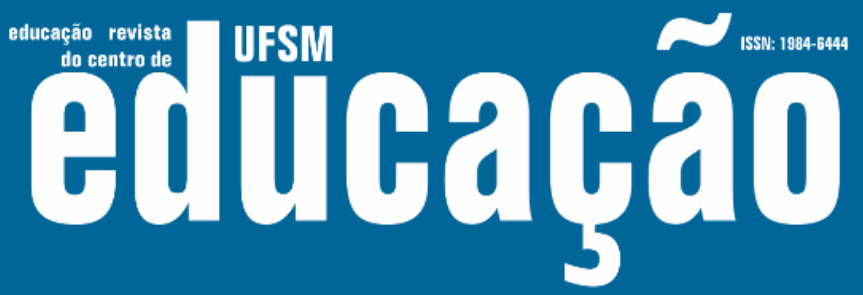

ISSN: 1984-6444 | http://dx.doi.org/10.5902/1984644432632

\section{Discentes}

Ao longo dos dez anos analisados, a UFRN recebeu 196 discentes de graduação com deficiência (Figura 1). Foram 76 discentes com dificuldades de aprendizagem, 41 com deficiência visual, 37 com limitação auditiva, $30 \mathrm{com}$ dificuldades motoras, 5 com deficiência intelectual, 5 com autismo e 2 com deficiência múltipla. Será que a quantidade de discentes teve relação com as deficiências abordadas nos projetos desenvolvidos?

Figura 1 - Quantidade de discentes de graduação na UFRN entre 2008 e 2017 por deficiência

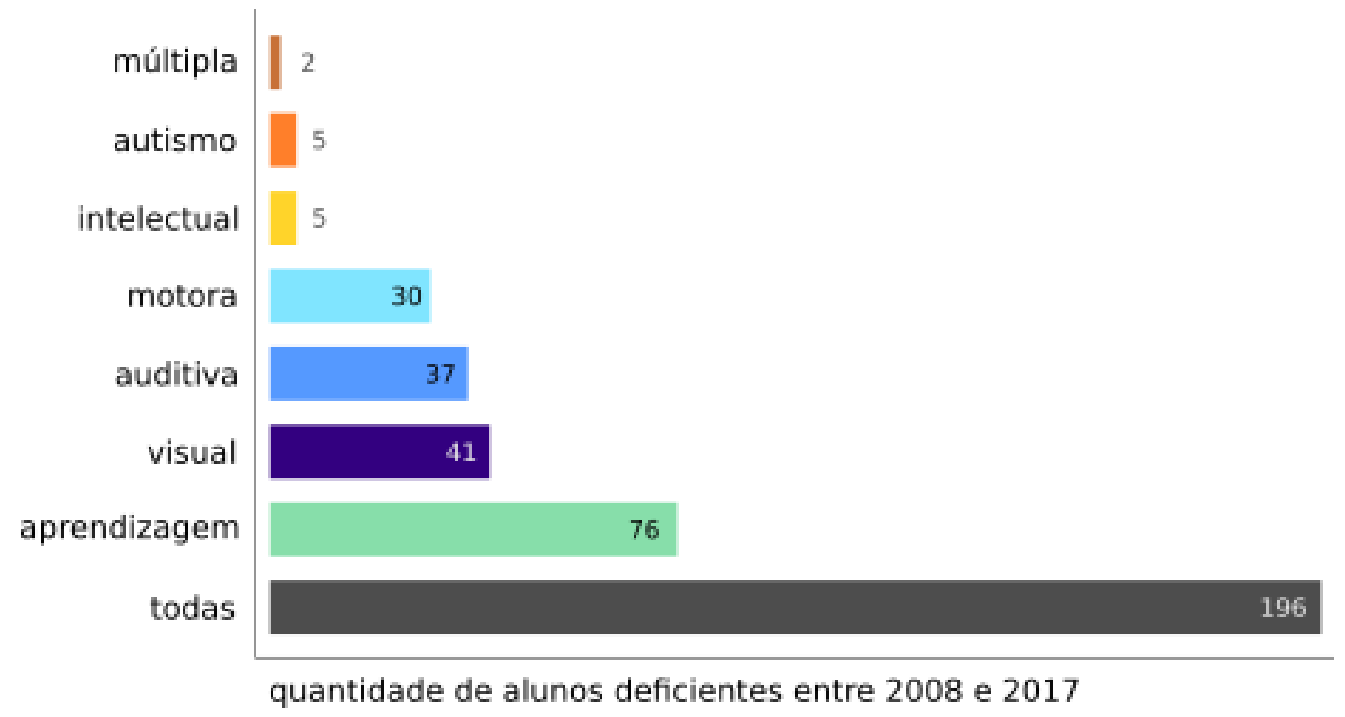

Fonte: Dados da CAENE e SINFO

\section{Projetos de extensão}

A quantidade de docentes da UFRN aumentou $244 \%$ no período analisado, sobretudo pelo REUNI (Planos de Reestruturação e Expansão das Universidades Federais). Essa expansão acompanhou a criação de centros na capital e no interior, como o Instituto Metrópole Digital e a Escola Multicampi de Ciências Médicas.

A Figura 2 apresenta a quantidade de docentes que desenvolveram projetos de extensão relacionados com deficiência, estratificada por centro e por ano de ingresso na universidade. Quanto mais alta a coluna, mais docentes daquele centro desenvolveram projetos de extensão. Essa quantidade total também está indicada de 


\section{T WFM

ISSN: 1984-6444 | http://dx.doi.org/10.5902/1984644432632

forma absoluta e como porcentagem em relação a todos os professores do centro. Quanto mais verde-escuro for a coluna, mais antigos na universidade são os professores que participaram desses projetos. Os centros da capital (esquerda) e do interior (direita) estão agrupados.

Figura 2 - Quantidade de docentes da UFRN em 2017 participantes de projetos de extensão relacionados com deficiência, por centro e ano de ingresso

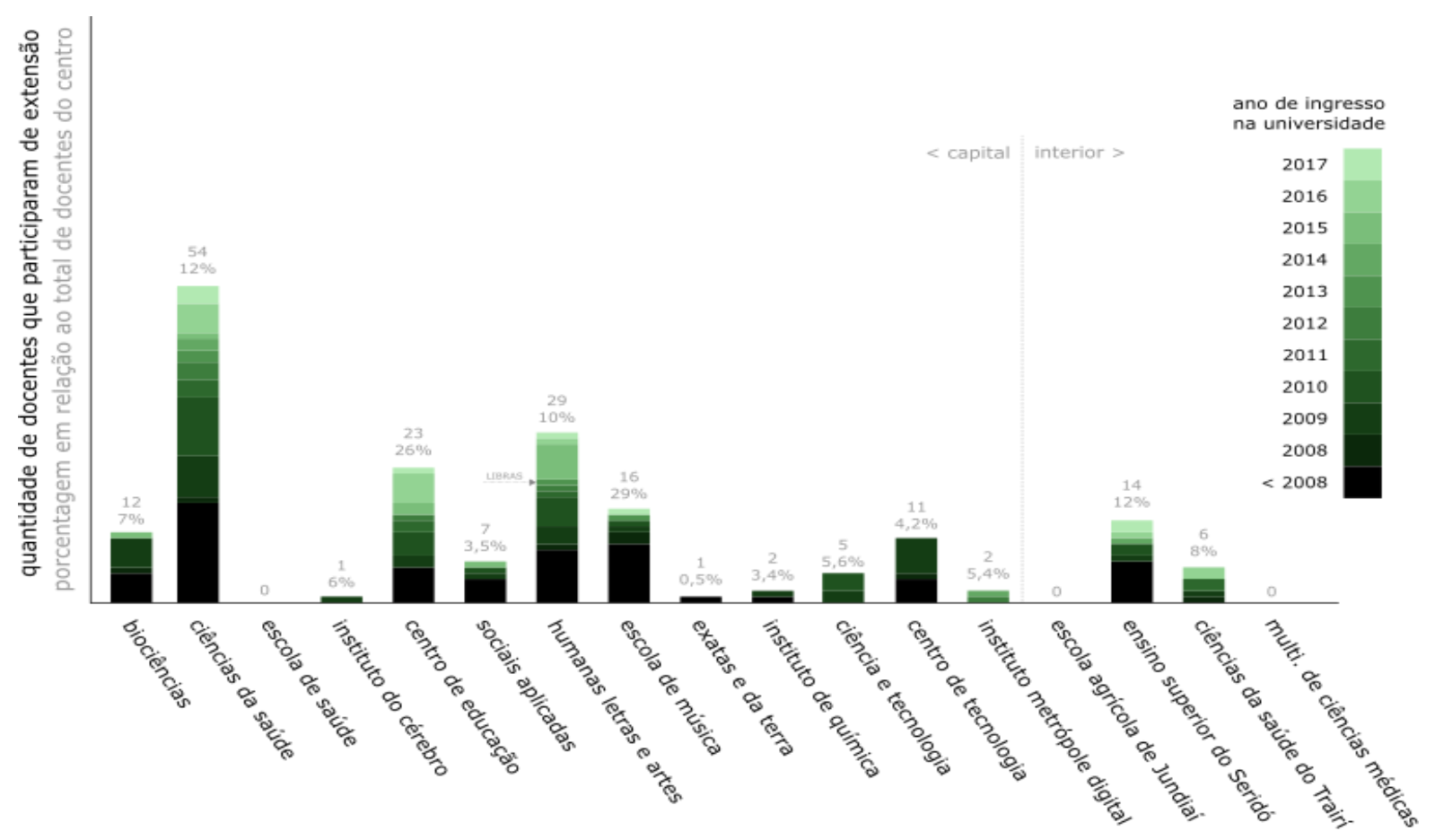

Fonte: Portal de Dados Abertos da UFRN

Em termos absolutos, o Centro de Ciências da Saúde (54 docentes), o Centro de Ciências Humanas, Letras e Artes (29 docentes) e o Centro de Educação (23 docentes) foram os centros com maior participação de docentes em projetos de extensão. Em termos proporcionais, A Escola de Música (29\%), o Centro de Educação (26\%), o Centro de Ciências da Saúde (12\%) e o Centro de Ensino Superior do Seridó (12\%) ficam nas três primeiras colocações. É interessante destacar que este último fica no interior. A maioria dos centros possui docentes envolvidos com extensão sobre 


\section{تutดaดูão}

ISSN: 1984-6444 | http://dx.doi.org/10.5902/1984644432632

deficientes, apesar de 5 centros possuírem menos de 5 docentes envolvidos e outros 3 centros não possuírem docentes envolvidos.

A área de atuação não foi decisiva para o envolvimento dos docentes em projetos de extensão. Por exemplo, 4 centros atuam na área da saúde, mas apenas 2 deles possuem docentes envolvidos. A predominância de tons escuros no gráfico indica que a maioria dos docentes envolvidos são mais antigos na UFRN (com quase ou mais de 10 anos). Entretanto, o ano de ingresso dos docentes na universidade também não foi determinante para sua participação em projetos de extensão, pois em vários centros existem muitos docentes antigos que não se envolveram e muitos docentes novos (com menos de 8 anos na UFRN) que se envolveram. É provável que o ano de ingresso na UFRN tenha relação com a idade dos docentes, ou seja, docentes antigos na instituição tendem a ser mais velhos. Assim, a idade também não parece ter sido determinante para o envolvimento dos docentes com extensão sobre deficiência.

Docentes de centros do interior também tiveram participação bem significativa em projetos de extensão sobre deficientes. Dois centros do interior superaram 6 centros da capital em números absolutos e 9 centros da capital em porcentagem de docentes.

A criação do curso de Letras - Língua Portuguesa e Libras em 2013 no Centro de Ciências Humanas, Letras e Artes apresentou um incremento no total de docentes envolvidos. Todavia, tal incremento não representou uma concentração de docentes novos, pois os antigos também se envolveram.

A Figura 3 apresenta a quantidade de projetos de extensão relacionados com deficiência por centro e por ano. Um projeto de extensão foi computado em cada centro dos seus participantes, então o mesmo projeto pode ter se repetido por vários centros. Quanto mais alta a coluna, mais projetos de extensão o centro desenvolveu. Quanto mais escura a coluna, mais antigos são os projetos de extensão. A ordem dos centros e a separação capital-interior permaneceram as mesmas.

Os centros com maior número de projetos são os mesmos com o maior número de docentes, mas a ordem muda: Centro de Ciências da Saúde (127 projetos), Centro de Educação (62 projetos), Centro de Ciências Humanas, Letras e Artes (55 projetos) 


\section{T WFM

ISSN: 1984-6444 | http://dx.doi.org/10.5902/1984644432632

e Escola de Música (45 projetos). Os demais centros aparecem com quantidade bem menor de projetos. Vale notar que o Centro de Ciências Sociais Aplicadas, responsável pelos cursos de Administração, Serviço Social e Biblioteconomia, por exemplo, executou uma quantidade menor de projetos do que centros da área de exatas e tecnológicas, como o Instituto de Química, o Centro de Tecnologia e a Escola de Ciência de Tecnologia.

Figura 3 - Quantidade de projetos de extensão na UFRN entre 2008 e 2017 relacionados com deficiência, por centro e ano de realização

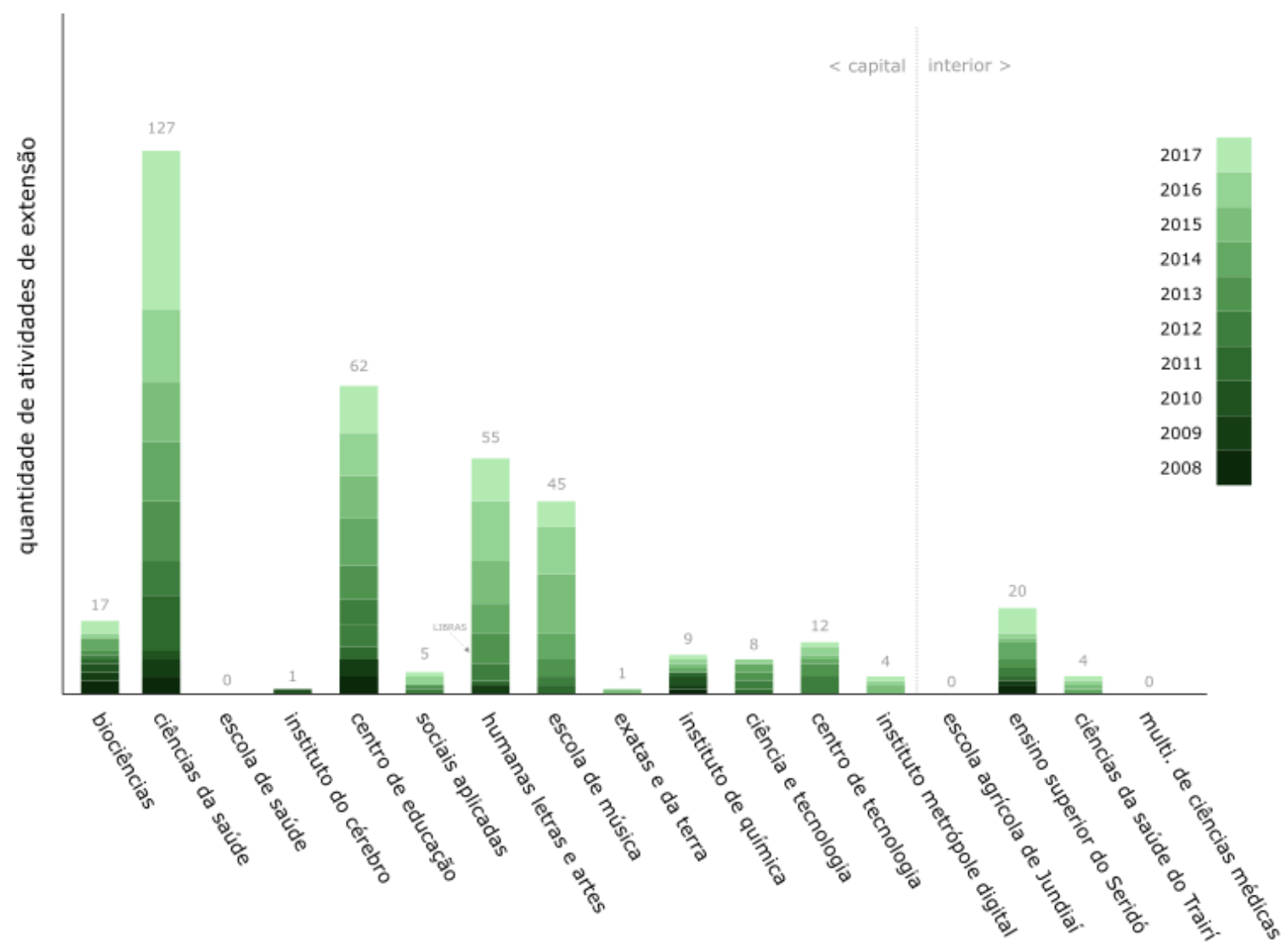

Fonte: Portal de Dados Abertos da UFRN e SIGAA

Existe pouco verde escuro no gráfico, indicando que os projetos de extensão aumentaram de volume nos últimos 7 ou 5 anos. Esse comportamento acompanha a criação da CAENE em 2010. Pelas cores também se percebe perenidade e boa 


\section{Autตaดูão}

ISSN: 1984-6444 | http://dx.doi.org/10.5902/1984644432632

distribuição dos projetos ao longo do período analisado na maioria dos centros, quase sem concentração anual significativa.

O interior teve boa quantidade de projetos de extensão, com 1 centro do interior executando mais projetos do que 9 centros da capital. Os centros que atuam na formação de professores na capital (Centro de Educação) e no interior (Centro de Ensino Superior do Seridó) apresentaram semelhança na perenidade dos projetos, apesar da diferença significativa no total. Houve um aumento na quantidade de projetos do Centro de Ciência Humanas, Letras e Artes após a criação do curso de Letras - Língua Portuguesa e Libras. Contudo, sua influência deve ter sido concomitante com a influência da CAENE, pois coincidiu com o aumento na quantidade de projetos em outros centros.

A Figura 4 apresenta a quantidade de projetos de extensão que aborda cada tipo de deficiência. Um total de 154 projetos abordaram deficiências em geral. Eles foram os de maior quantidade em quase metade dos centros. Contra 279 projetos que abordam tipos específicos de deficiência: 98 para auditiva (35\%), 85 para visual (30,5\%), 44 para intelectual (15,7\%), 35 para motora (12,5\%), 11 para aprendizagem $(3,9 \%)$ e 6 para autismo $(2,1 \%)$. Os cursos de Letras - Língua Portuguesa e Libras e Fonoaudiologia influenciaram significativamente a quantidade total de projetos que abordam a deficiência auditiva (35\%), ainda que esta não seja a deficiência de maior incidência entre os discentes com deficiência na UFRN (19\%). Também vale notar que o maior grupo (38\%) de alunos com deficiência na universidade possui dificuldades de aprendizagem e que esta foi uma das deficiências menos abordadas por projetos de extensão $(3,9 \%)$. 


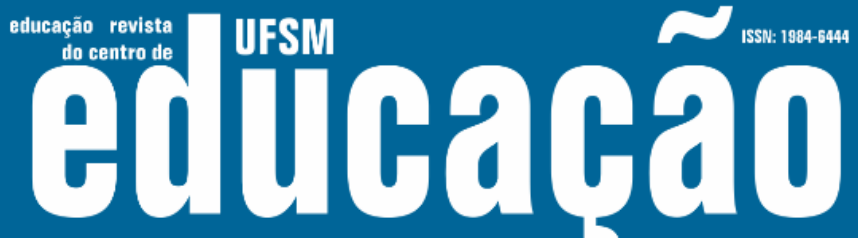

ISSN: 1984-6444 | http://dx.doi.org/10.5902/1984644432632

Figura 4 - Quantidade de projetos de extensão na UFRN entre 2008 e 2017 relacionados com deficiência, por deficiência e por centro

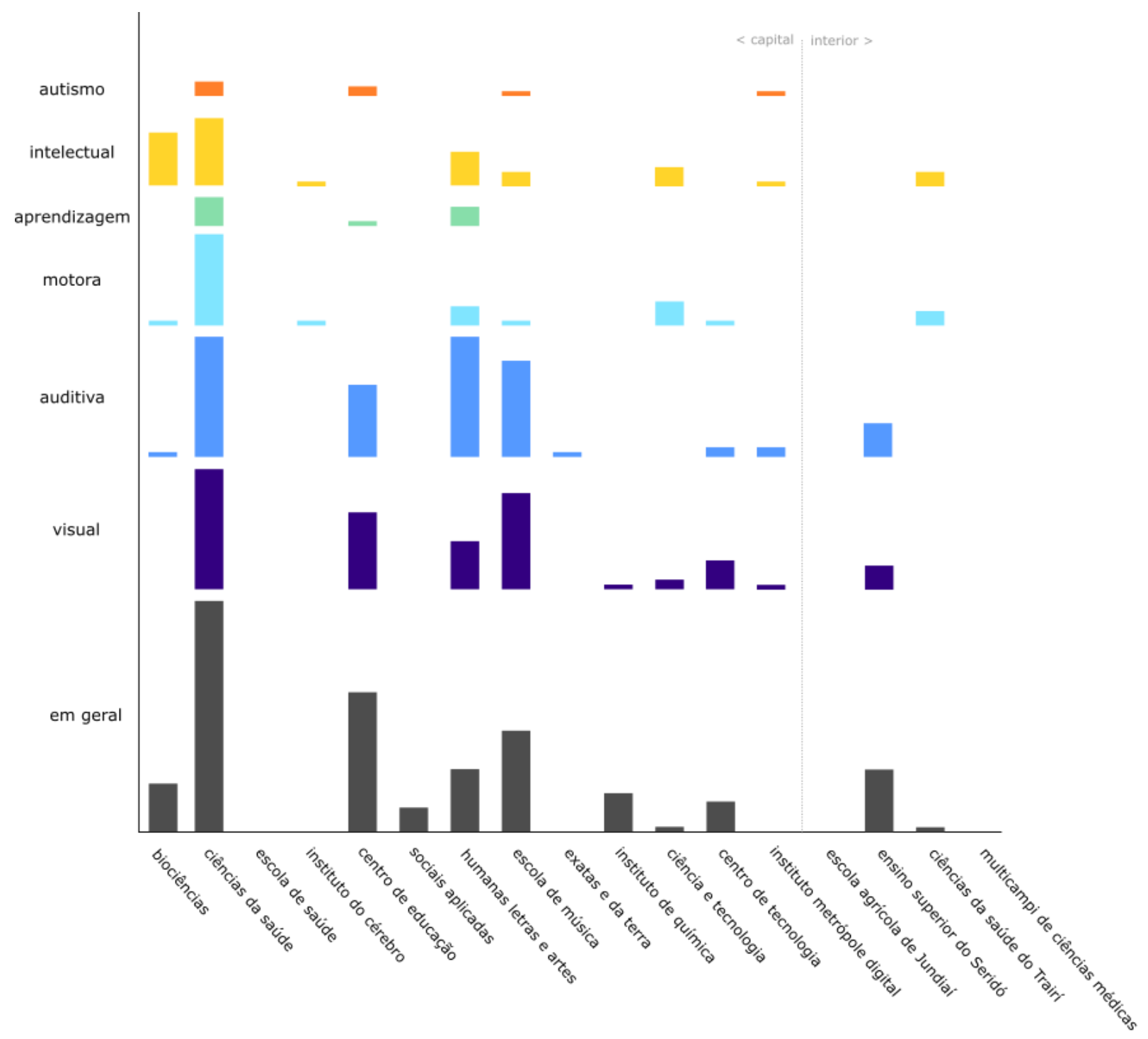

Fonte: Portal de Dados Abertos da UFRN e SIGAA

As deficiências visual, motora, auditiva e intelectual foram abordadas por 8 ou 9 centros, já as deficiências de aprendizagem e autismo por 3 ou 4 centros. O único centro que abordou todas as deficiências foi o Centro de Ciências da Saúde. Os que abordam 4 ou 5 deficiências individualmente também são aqueles com maior número de projetos e mais um inesperado: Centro de Educação, Centro de Ciências Humanas, Letras e Artes, Escola de Música e Instituto Metrópole Digital. Este último abordou 4 deficiências individualmente em apenas 4 projetos executados. É uma alta 


\section{Uism Futlaghã}

ISSN: 1984-6444 | http://dx.doi.org/10.5902/1984644432632

diversidade de atuação para um centro tecnológico criado no final de 2012. Os demais centros tiveram atuação bastante concentrada, com destaque para o Centro de Ciências Exatas e da Terra e o Instituto de Química atuando em apenas uma deficiência específica. Quase todos os tipos de deficiência abordados em projetos de extensão na capital também foram abordados no interior, exceto autismo e aprendizagem apenas na capital. No interior, as deficiências visuais e auditivas foram foco do Centro de Ensino Superior do Seridó, que se concentra na formação de professores, enquanto que as deficiências motora e intelectual foram foco da Faculdade de Ciências da Saúde do Trairi. 


\section{F HEM

ISSN: 1984-6444 | http://dx.doi.org/10.5902/1984644432632

Figura 5 - Quantidade de projetos de extensão na UFRN entre 2008 e 2017 relacionados com deficiência, por tema e por centro

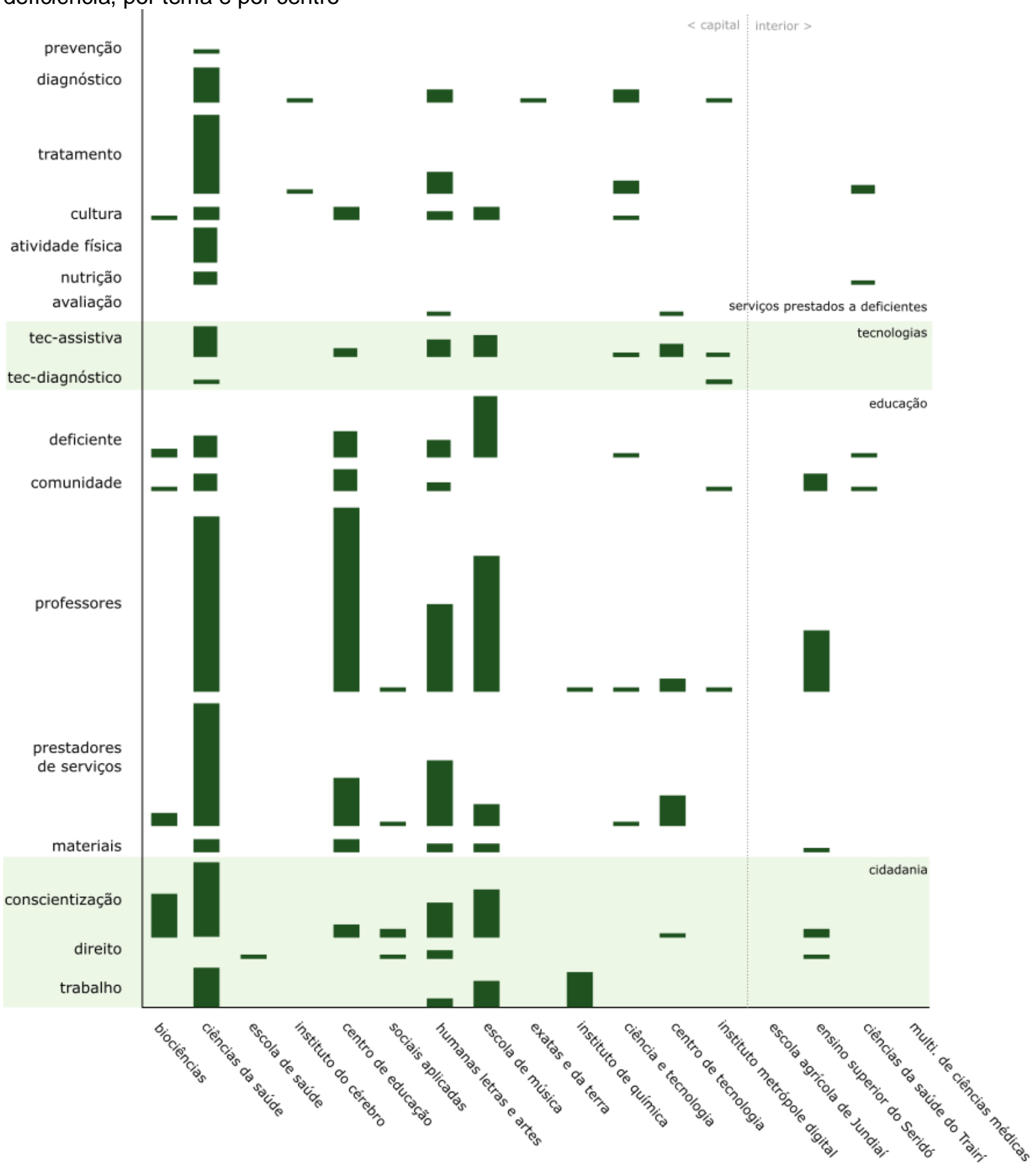

Fonte: Portal de Dados Abertos da UFRN e SIGAA

A Figura 5 representa a quantidade de projetos de extensão que abordaram temas específicos, desde educação até prestação de serviços, tecnologias e cidadania. Mesmo em educação, os projetos não se limitaram a temas tradicionais 


\section{T- ussm,

ISSN: 1984-6444 | http://dx.doi.org/10.5902/1984644432632

como a formação de professores, a formação do próprio deficiente e materiais didáticos. Alguns projetos abordaram também a formação daqueles que convivem com o deficiente e a formação de prestadores de serviço para pessoas com deficiência. Quase todos os temas identificados nesta pesquisa foram encontrados em extensão, exceto pessoa com deficiência, desenvolvimento de software, transporte e tecnologias de tratamento. A variedade de temas foi observada em todos os centros, tanto na capital quanto no interior. Aqueles com maior quantidade de projetos também apresentaram uma grande variedade de temas. Mesmo aqueles com poucos projetos tiveram uma boa variedade, como o Instituto Metrópole Digital, na capital, e a Faculdade de Ciências da Saúde do Trairi, no interior. 


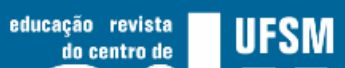 Ellibahá}

ISSN: 1984-6444 | http://dx.doi.org/10.5902/1984644432632

Figura 6 - Quantidade de projetos de extensão na UFRN entre 2008 e 2017 relacionados com deficiência, por tema e por deficiência

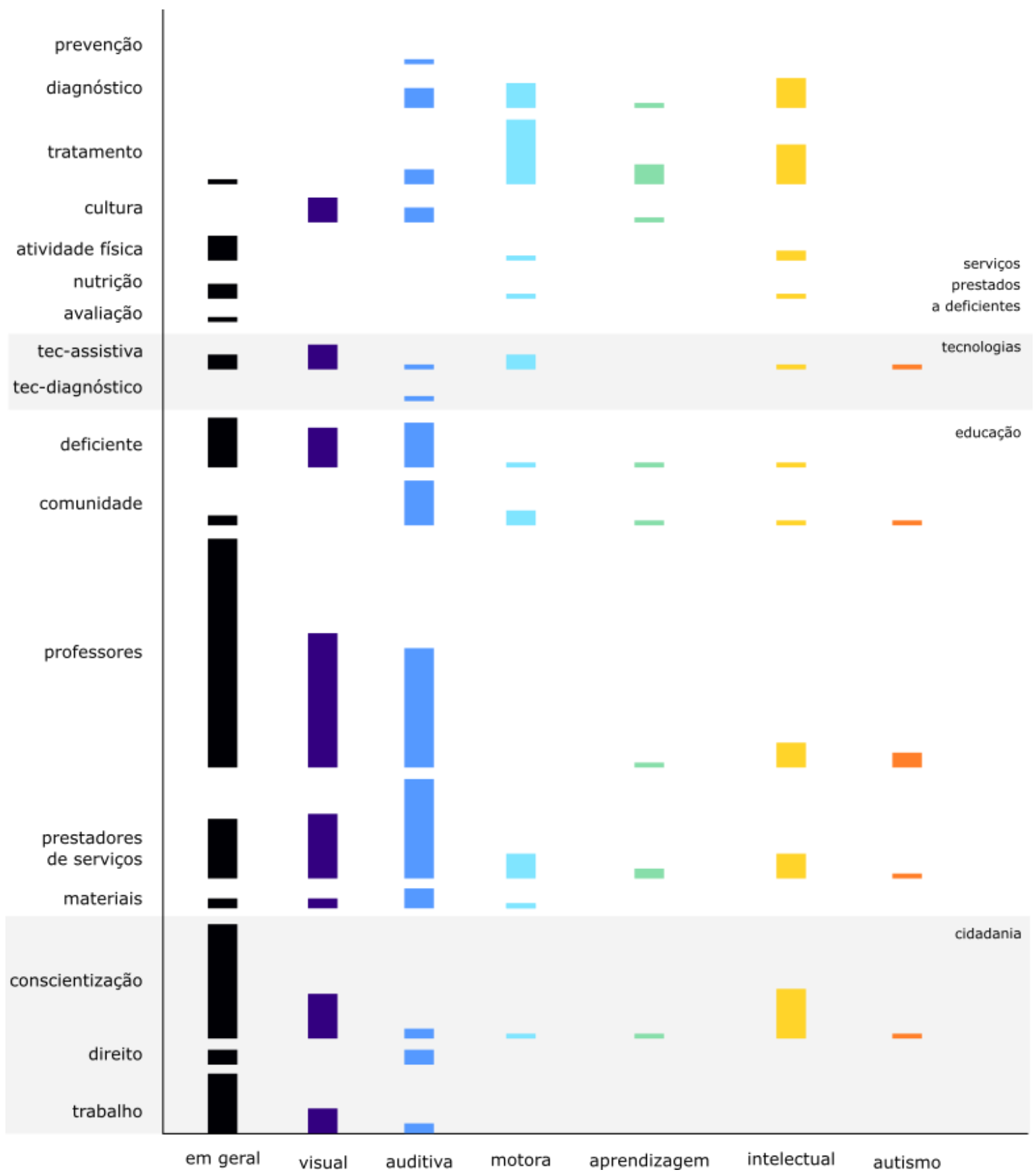

Fonte: Portal de Dados Abertos da UFRN e SIGAA

A Figura 6 indica a quantidade de projetos de extensão que abordam determinadas deficiências em determinados temas. Cidadania e educação foram abordadas para deficiências de forma geral e todas as demais. Tecnologias e serviços 


\section{Eilthapão

ISSN: 1984-6444 | http://dx.doi.org/10.5902/1984644432632

foram abordados para deficiências de forma geral; e quase todas as outras, exceto as tecnologias, para dificuldades de aprendizagem e o autismo para os serviços.

Numa leitura mais detalhada da Figura 6, é possível identificar, por exemplo, muitos projetos de extensão que abordam a formação de professores considerando deficiências auditivas e visuais e quase nenhum projeto considerando deficiências de aprendizagem. Professores quase não enfrentam as dificuldades de aprendizagem em sala de aula? Outro exemplo, a nutrição foi abordada em projetos apenas para pessoas com deficiência motora ou intelectual. Será que cegos, surdos ou autistas também não precisariam de um apoio/orientação nutricional específico? Este resultado visual pode ser usado como um importante instrumento para reflexão sobre o que a UFRN tem feito em extensão e o que ela ainda pode desenvolver. Algo semelhante pode ser feito para outras instituições.

Figura 7 - Colaboração entre docentes em projetos de extensão na UFRN entre 2008 e 2017 relacionados com deficiência.

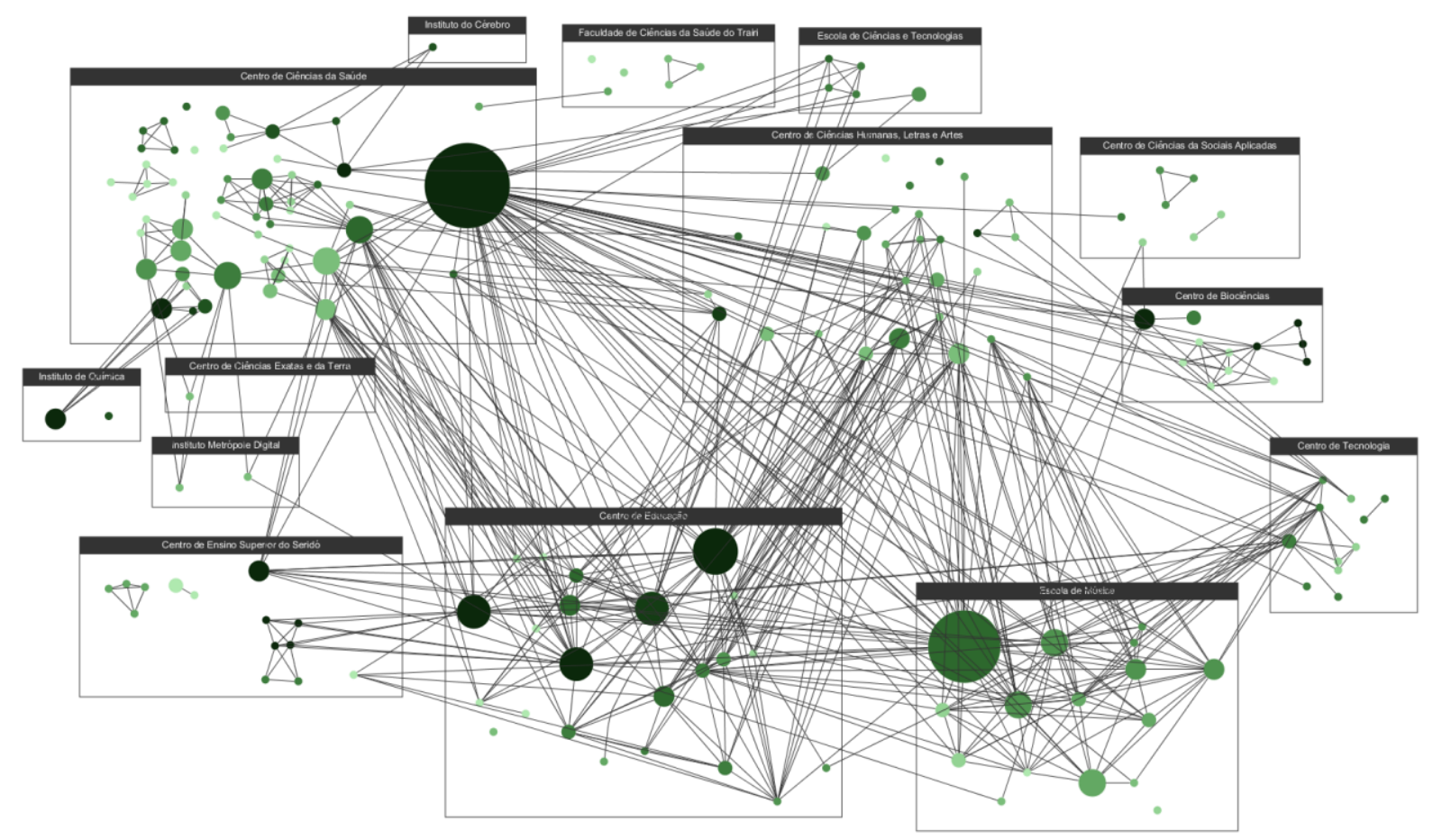

Fonte: Portal de Dados Abertos da UFRN e SIGAA

A Figura 7 ilustra a colaboração entre docentes da UFRN durante projetos de extensão relacionados com deficiência. Retângulos representam centros, círculos 


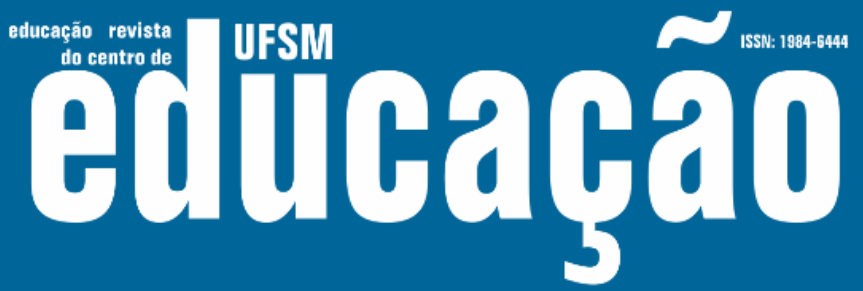

ISSN: 1984-6444 | http://dx.doi.org/10.5902/1984644432632

representam docentes e linhas, colaboração. Quanto maior o círculo, mais projetos de extensão o docente participou. Quanto mais escuro for os círculos, há mais tempo o docente participou dos projetos de extensão analisados.

As diversas linhas indicam interações dentro dos centros e entre centros. Nenhum centro ficou isolado. Poucos são os docentes que trabalharam sozinhos ou em grupos pequenos e isolados. Na maioria das vezes houve uma boa colaboração entre docentes. É importante destacar as colaborações entre centros do interior e da capital, como aquelas entre docentes do Centro de Ensino Superior do Seridó, no interior, com os do Centro de Educação e do Centro de Ciências da Saúde, na capital. Essa colaboração entre centros é um indício de que os projetos de extensão relacionados com deficiência costumam ter um carácter interdisciplinar forte na UFRN.

\section{Projetos de pesquisa}

A Figura 8 apresenta a quantidade de docentes que desenvolveram projetos de pesquisa relacionada com deficiência, estratificada por centro e por ano de ingresso do docente na universidade. Essa quantidade é indicada pela altura da coluna, por um valor absoluto e pela porcentagem em relação ao total de docentes do centro. Quanto mais antigo for o docente na universidade, mais escura fica a coluna. Os centros à esquerda ficam na capital e os da direita ficam no interior.

Em números absolutos, o Centro de Ciências da Saúde (62 docentes), o Centro de Tecnologia (33 docentes) e o Centro de Ciências Humanas, Letras e Artes (25 docentes) possuem maior participação de docentes em projetos de pesquisa sobre 0 tema deficiência. Proporcionalmente, a Faculdade de Ciências Médicas do Trairi (22\%), criada em 2008 no interior, o Centro de Educação (19\%), o Centro de Ciências da Saúde (13\%), criados antes de 2008, e o Instituto Metrópole Digital (13\%), criado em 2013, ocupam as três primeiras colocações. 


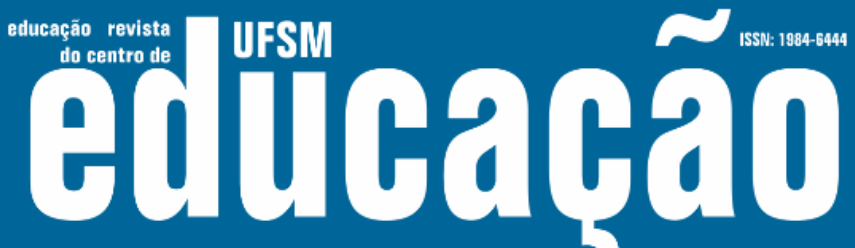

ISSN: 1984-6444 | http://dx.doi.org/10.5902/1984644432632

Figura 8 - Quantidade de docentes da UFRN em 2017 participantes de projetos de pesquisa relacionada com deficiência, por centro e ano de ingresso.

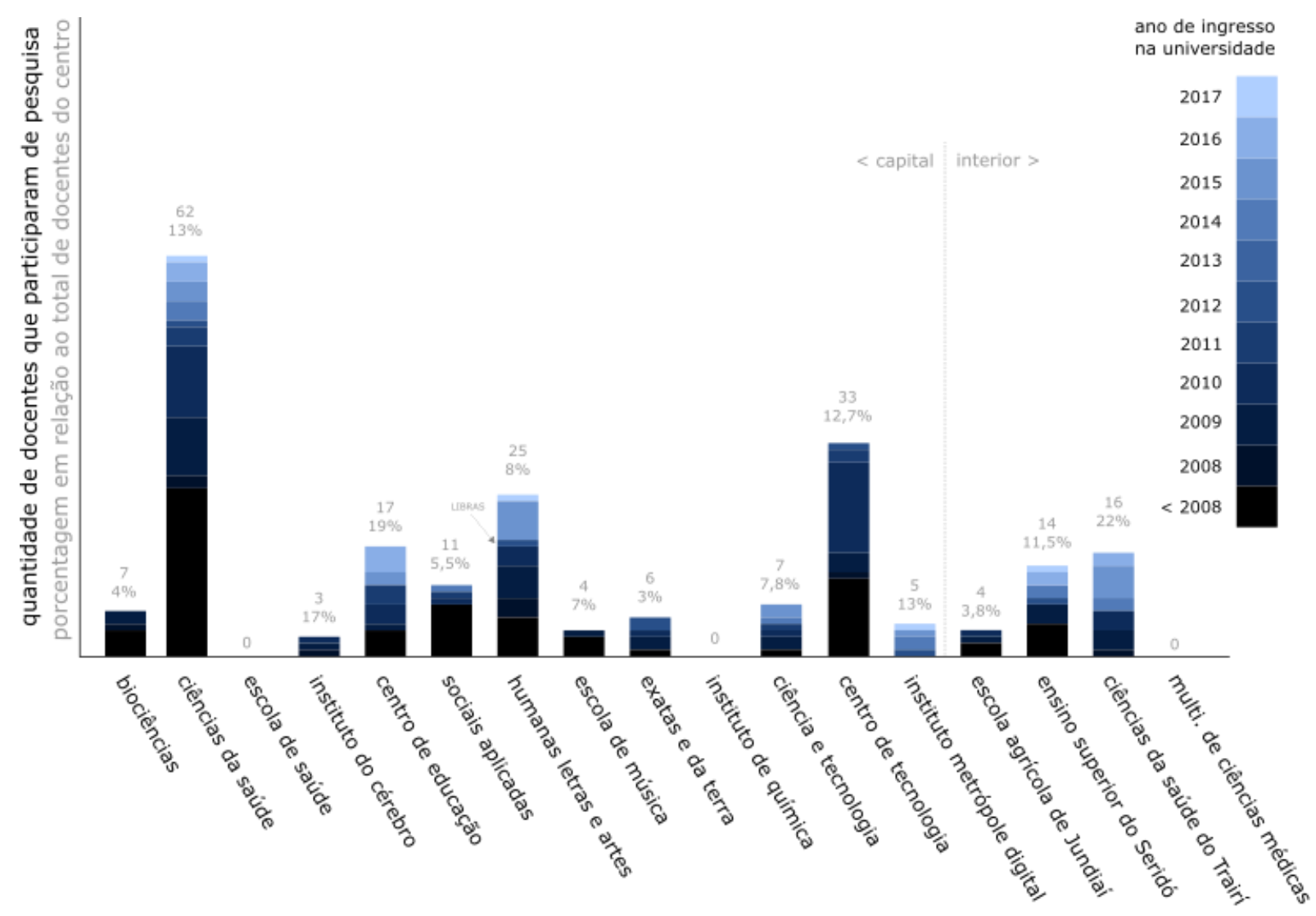

Fonte: Portal de Dados Abertos da UFRN e SIGAA

A maioria dos centros possui docentes envolvidos com pesquisa relacionada com deficiência. Três centros não possuem docentes envolvidos. A área de atuação do centro não determinou o envolvimento dos seus docentes. Apesar de existirem 4 centros com atuação na área de saúde, por exemplo, somente 2 deles tiveram docentes envolvidos. A predominância de tons de azul escuro no gráfico indica que a maioria dos docentes envolvidos são antigos (com quase ou mais de 10 anos) na universidade. Entretanto, o ano de ingresso dos docentes na UFRN não determinou sua participação em projetos de pesquisa, pois em vários centros existem muitos docentes antigos que não se envolveram e muitos docentes novos (com menos de 8 anos na UFRN) que se envolveram. Como a idade do docente costuma acompanhar seu ano de ingresso na universidade, provavelmente a pesquisa relacionada com deficiência foi conduzida por alguns docentes mais jovens e a maioria mais madura. 


\section{F HWM

ISSN: 1984-6444 | http://dx.doi.org/10.5902/1984644432632

Docentes de centros do interior tiveram participação significativa em pesquisas relacionada com deficiência. Dois centros do interior superaram 9 centros da capital em números absolutos e 8 centros da capital em porcentagem de docentes. A criação do curso de Letras - Língua Portuguesa e Libras em 2013 no Centro de Ciências Humanas, Letras e Artes incrementou o total de docentes envolvidos. Contudo, isso não representou concentração de docentes novos, pois os antigos também se envolveram.

Figura 9 - Quantidade de projetos de pesquisa na UFRN entre 2008 e 2017 relacionada com deficiência, por centro e ano de realização.

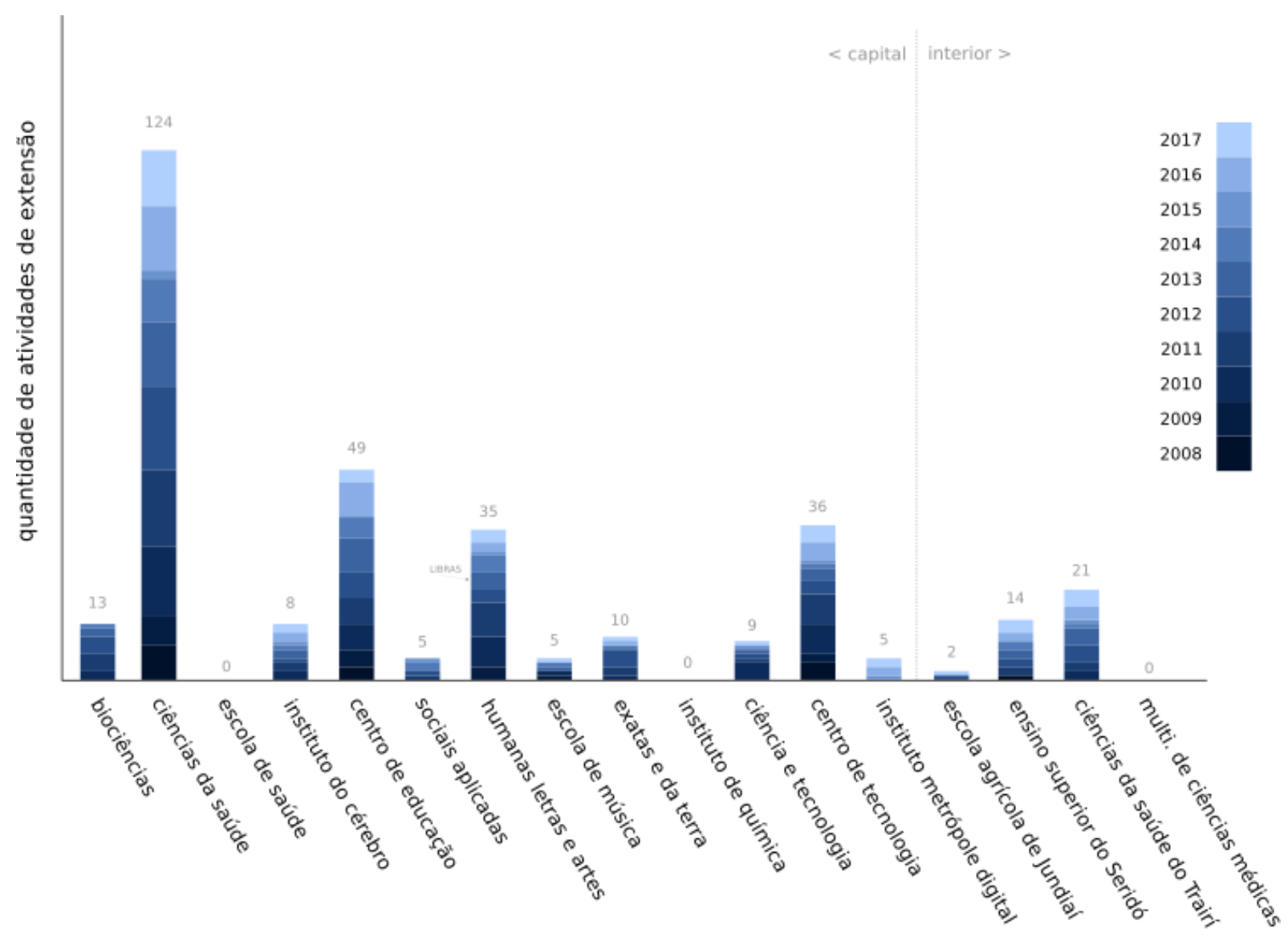

Fonte: Portal de Dados Abertos da UFRN e SIGAA

A Figura 9 indica a quantidade de projetos de pesquisa relaciona com deficiência por centro e por ano. Um projeto de pesquisa foi computado em cada centro dos seus participantes. Assim, o mesmo projeto pode ter se repetido em vários centros. Quanto mais alta for a coluna, mais projetos de pesquisa o centro 


\section{F HEM Eulloahá}

ISSN: 1984-6444 | http://dx.doi.org/10.5902/1984644432632

desenvolveu. Quanto mais escura a coluna, mais antigos são os projetos de pesquisa. A ordem dos centros e separação capital-interior permaneceram as mesmas. Nem todos centros com mais projetos de pesquisa foram os mesmos com mais docentes. O Centro de Ciências da Saúde (124 projetos) continuou em primeiro lugar. Em segundo lugar apareceu o Centro de Educação (49 projetos), que anteriormente estava em quarto. Em terceiro lugar encontra-se o Centro de Tecnologia (36 projetos), que estava em segundo. Novamente vale notar que o Centro de Ciências Sociais Aplicadas realizou menos projetos de pesquisa do que centros da área de exatas e tecnológicas, como o Centro de Ciências Exatas e da Terra, a Escola de Ciência e Tecnologia e o Centro de Tecnologia.

Quando comparadas as quantidades de projetos de pesquisa e de extensão, fica evidente o caráter extensionista ou de geração de conhecimento de cada centro no que diz respeito à pessoa com deficiência. Por exemplo, o Centro de Ciências Exatas e da Terra, a Faculdade de Ciências da Saúde do Trairi e o Instituto do Cérebro realizaram pesquisas neste tema, apesar de quase não terem se envolvido com extensão. A Escola de Música e o Instituto de Química tiveram atuação extensionista muito relevante relacionada com deficiência, apesar de realizarem pouca ou nenhuma pesquisa a respeito. Mesmo tendo executado uma quantidade razoável de projetos de extensão, o Centro de Tecnologia se envolveu em 3 vezes mais projetos de pesquisa do que de extensão. A Escola de Saúde, na capital, e a Escola Multicampi de Ciências Médicas, no interior, foram os únicos centros que não realizaram pesquisa nem extensão relacionadas com deficiência.

Os projetos de pesquisa foram perenes, com melhor distribuição ao longo dos anos do que os projetos de extensão. Não houve alta concentração de projetos de pesquisa ao longo do período analisado, apesar de existirem mais projetos de pesquisa antigos (entre 2008-2012). A quantidade de projetos de pesquisa parece não ter tido influência significativa da CAENE, criada em 2010, enquanto que os projetos de extensão aumentaram nos últimos 7 ou 5 anos. Talvez a CAENE tenha estimulado a regularidade dos projetos de pesquisa. Diferente do que ocorreu em projetos de extensão, a quantidade de projetos de pesquisa no Centro de Ciências Humanas, 


\section{F HEM entuabal}

ISSN: 1984-6444 | http://dx.doi.org/10.5902/1984644432632

Letras e Artes não aumentou após a criação do curso de Letra - Língua Portuguesa e Libras.

O interior também teve atuação significativa em projetos de pesquisa. Dois centros do interior realizaram mais projetos do que 9 centros da capital. Centros que atuam na mesma área na capital e no interior tiveram regularidade semelhante em projetos de pesquisa, apesar da diferença significativa na quantidade. O Centro de Educação, na capital, teve regularidade semelhante ao Centro de Ensino Superior do Seridó, no interior. O Centro de Ciências da Saúde, na capital, teve regularidade semelhante à Faculdade de Ciências da Saúde do Trairi, no interior.

A Figura 10 apresenta a quantidade de projetos de pesquisa que abordam cada tipo de deficiência. Um total de 91 projetos de pesquisa abordaram deficiências em geral, menos 63 projetos (59\%) do que os de extensão. Eles foram a maior parte dos projetos de pesquisa no Centro de Ciências Sociais Aplicadas (80\%), Centro de Educação Superior do Seridó (71\%), Centro de Educação (50\%) e na Escola de Música (40\%). Outros 247 projetos de pesquisa abordam deficiências específicas: 119 para motora $(48 \%), 36$ para visual $(14,5 \%), 36$ para auditiva $(14,5 \%), 23$ para intelectual (9,3\%), 22 para autismo (8,9\%) e 11 para aprendizagem $(4,5 \%)$. Diferente de extensão, os cursos de Letras - Língua Portuguesa e Libras e Fonoaudiologia não parecem ter direcionado um grande número de projetos de pesquisa para abordar a deficiência auditiva. Vale notar que o maior grupo (38\%) de alunos com deficiência na universidade possuem dificuldades de aprendizagem e esta foi a deficiência com o menor número $(4,5 \%)$ de projetos de pesquisa, similar à extensão. Deficiência motora foi pesquisada em 10 centros, deficiência visual em 9 centros, auditiva e autismo em 7 centros, intelectual em 6 e aprendizagem em apenas 3. Curioso observar que dificuldades de aprendizagem e deficiências motoras não foram pesquisadas em centros da área de educação. Apenas o Centro de Ciências da Saúde e o Centro de Ciências Humanas, Letras e Artes abordaram todos os tipos de deficiência em suas pesquisas no período. Todos os tipos de deficiências foram abordados em pesquisas na capital, enquanto que no interior não ocorreram pesquisas sobre deficiência auditiva e de aprendizagem. 


\section{تilloapão}

ISSN: 1984-6444 | http://dx.doi.org/10.5902/1984644432632

Figura 10 - Quantidade de projetos de pesquisa na UFRN entre 2008 e 2017 relacionados com deficiência, por deficiência e por centro

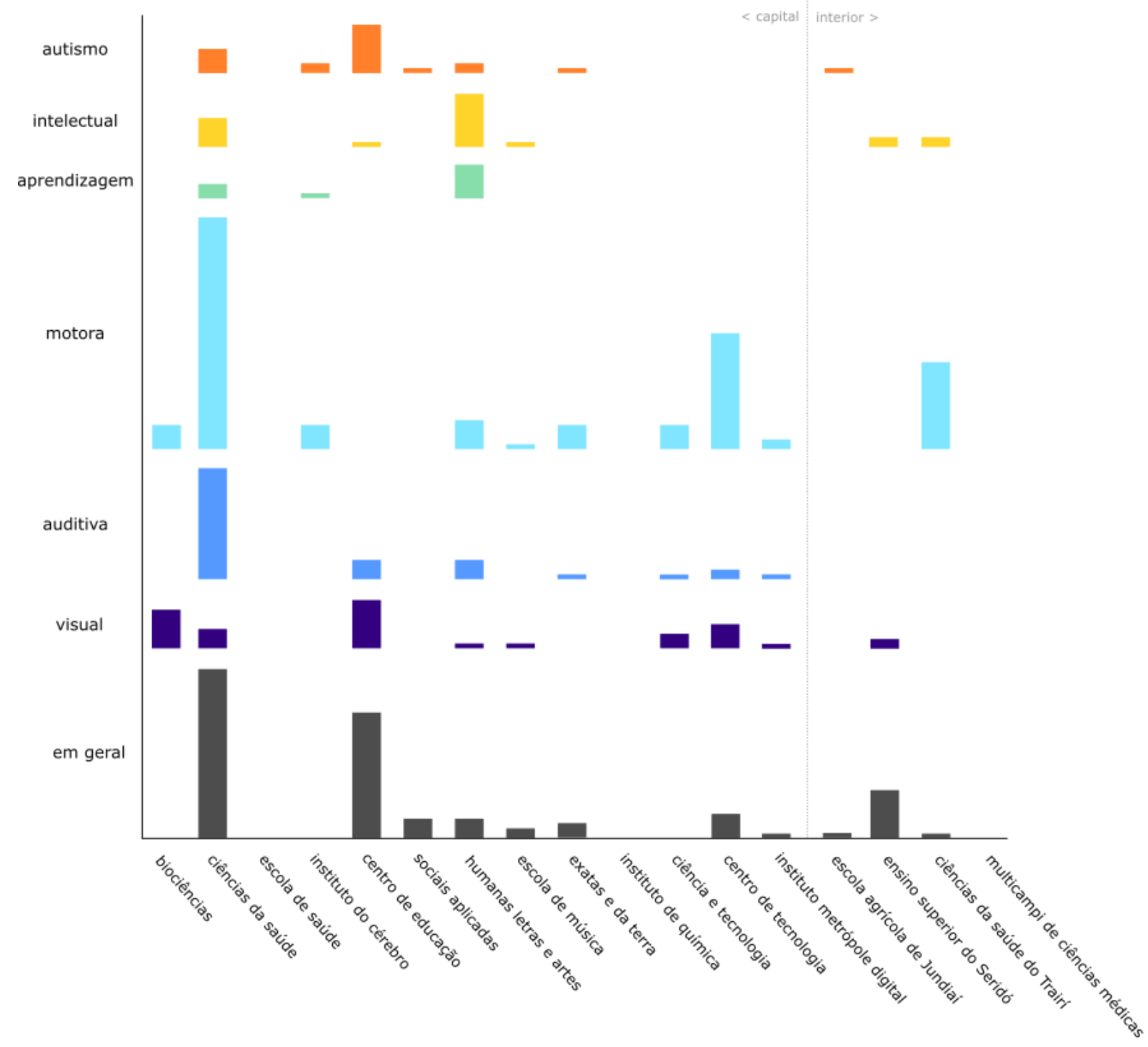

Fonte: Portal de Dados Abertos da UFRN e SIGAA

A Figura 11 ilustra a quantidade de projetos de pesquisa que abordam temas sobre educação, prestação de serviços, tecnologias, cidadania e pessoa com deficiência. Não houve projeto de extensão sobre este último tema, provavelmente porque está mais relacionado com geração de conhecimento. Pesquisas sobre educação não se limitaram a temas tradicionais como formação de professores, formação da pessoa com deficiência e materiais didáticos, similar à extensão. Elas também abordaram a formação daqueles que convivem com deficientes e a formação 


\section{Usis

ISSN: 1984-6444 | http://dx.doi.org/10.5902/1984644432632

de prestadores de serviço para pessoas com deficiência. Quase todos os temas foram abordados em pesquisas, exceto físico e conscientização. Todos os centros da capital e do interior apresentaram grande variedade de temas, independente da quantidade total de projetos de pesquisa.

Figura 11 - Quantidade de projetos de pesquisa na UFRN entre 2008 e 2017 relacionados com deficiência, por tema e por centro.

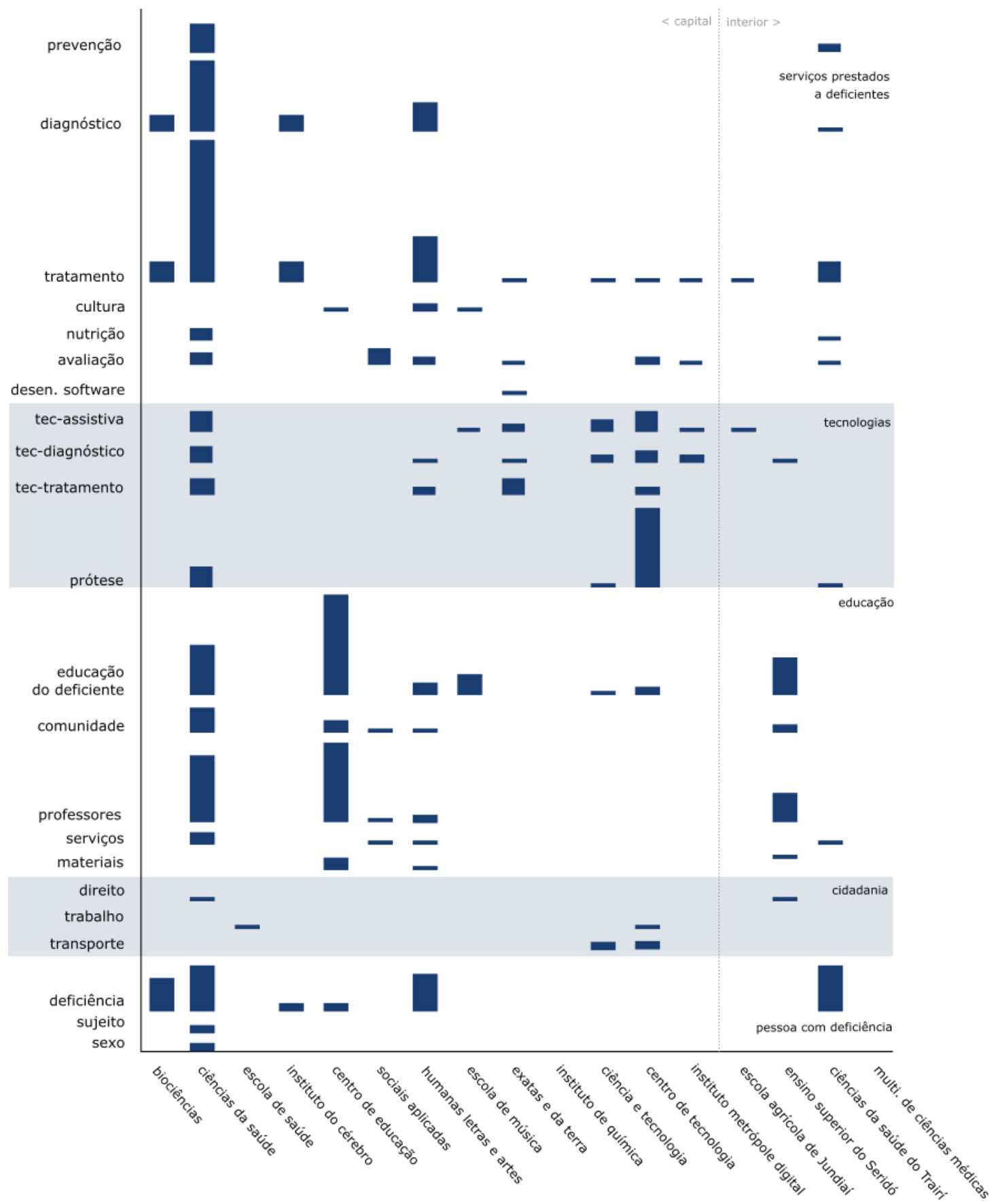

Fonte: Portal de Dados Abertos da UFRN e SIGAA 


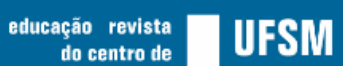 \\ ISSN: 1984-6444

ISSN: 1984-6444 | http://dx.doi.org/10.5902/1984644432632

Figura 12 - Quantidade de projetos de pesquisa na UFRN entre 2008 e 2017 relacionados com deficiência, por tema e por deficiência

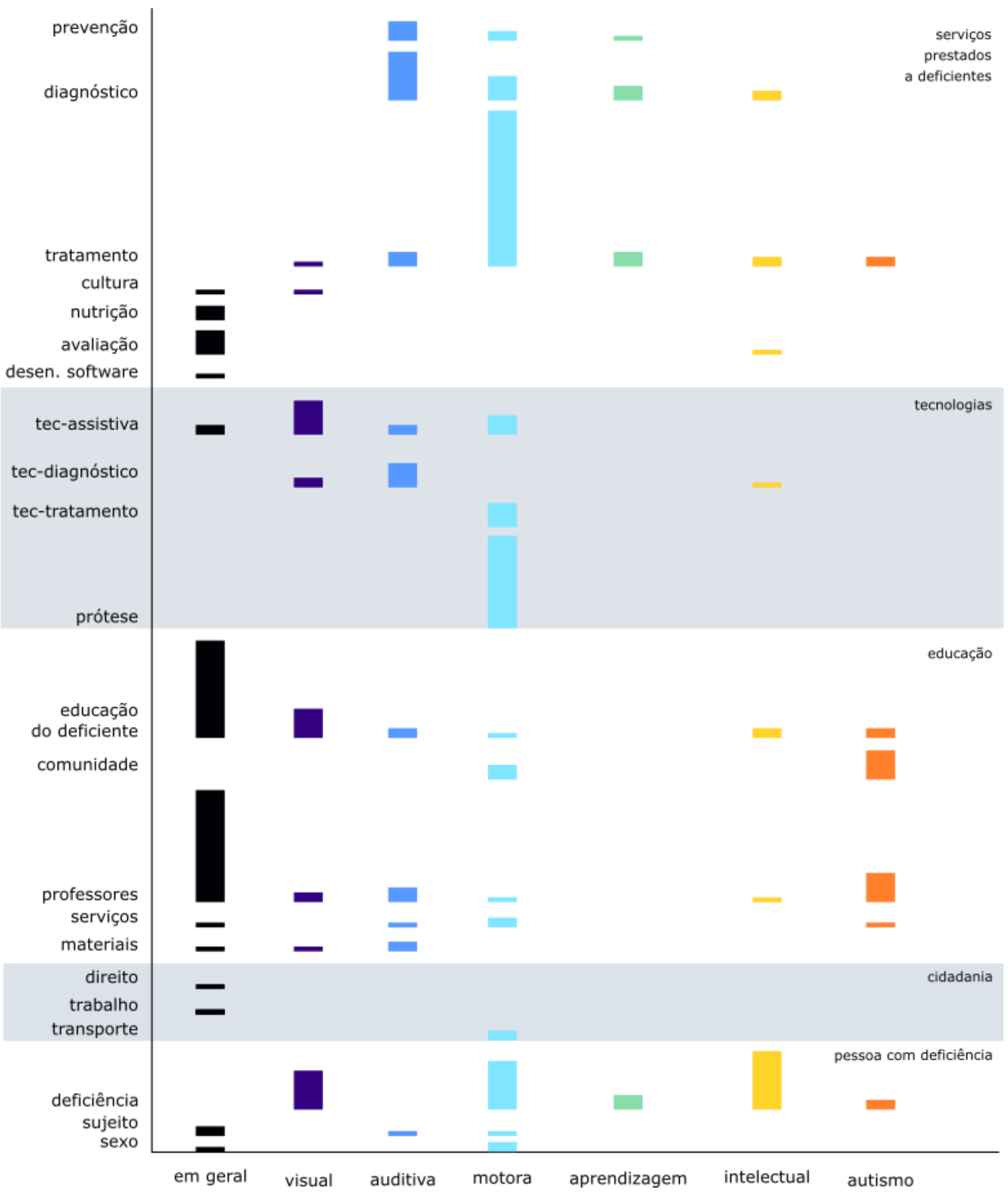

Fonte: Portal de Dados Abertos da UFRN e SIGAA

A Figura 12 indica a quantidade de projetos de pesquisa que abordam certas deficiências em determinados temas, agrupados por prestação de serviços, 


\section{Eilthapão

ISSN: 1984-6444 | http://dx.doi.org/10.5902/1984644432632

tecnologias, educação, cidadania e pessoa com deficiência. Todos os grupos de temas foram abordados em pesquisas sobre deficiências em geral e sobre deficiência motora em particular. Pesquisas sobre tecnologias não abordaram apenas autismo e dificuldades de aprendizagem. Curiosamente, as pesquisas sobre educação não abordaram somente as dificuldades de aprendizagem. Pesquisas sobre cidadania não consideraram a deficiência visual, auditiva, intelectual, de aprendizagem e autismo especificamente. Este gráfico é um importante instrumento para reflexão sobre o que a UFRN tem pesquisado e o que ela ainda pode pesquisar. Algo semelhante pode ser utilizado por outras instituições.

A Figura 13 ilustra a colaboração entre docentes da UFRN durante pesquisas relacionadas com deficiência no período analisado. Retângulos representam centros, círculos representam docentes e linhas, a colaboração. Quanto maior o círculo, mais projetos o docente participou. Quanto mais escuro for o tom de azul do círculo, há mais tempo o docente participou de projetos de pesquisa desse tipo.

Figura 13 - Colaboração entre professores em projetos de pesquisa na UFRN entre 2008 e 2017 relacionadas com deficiência.

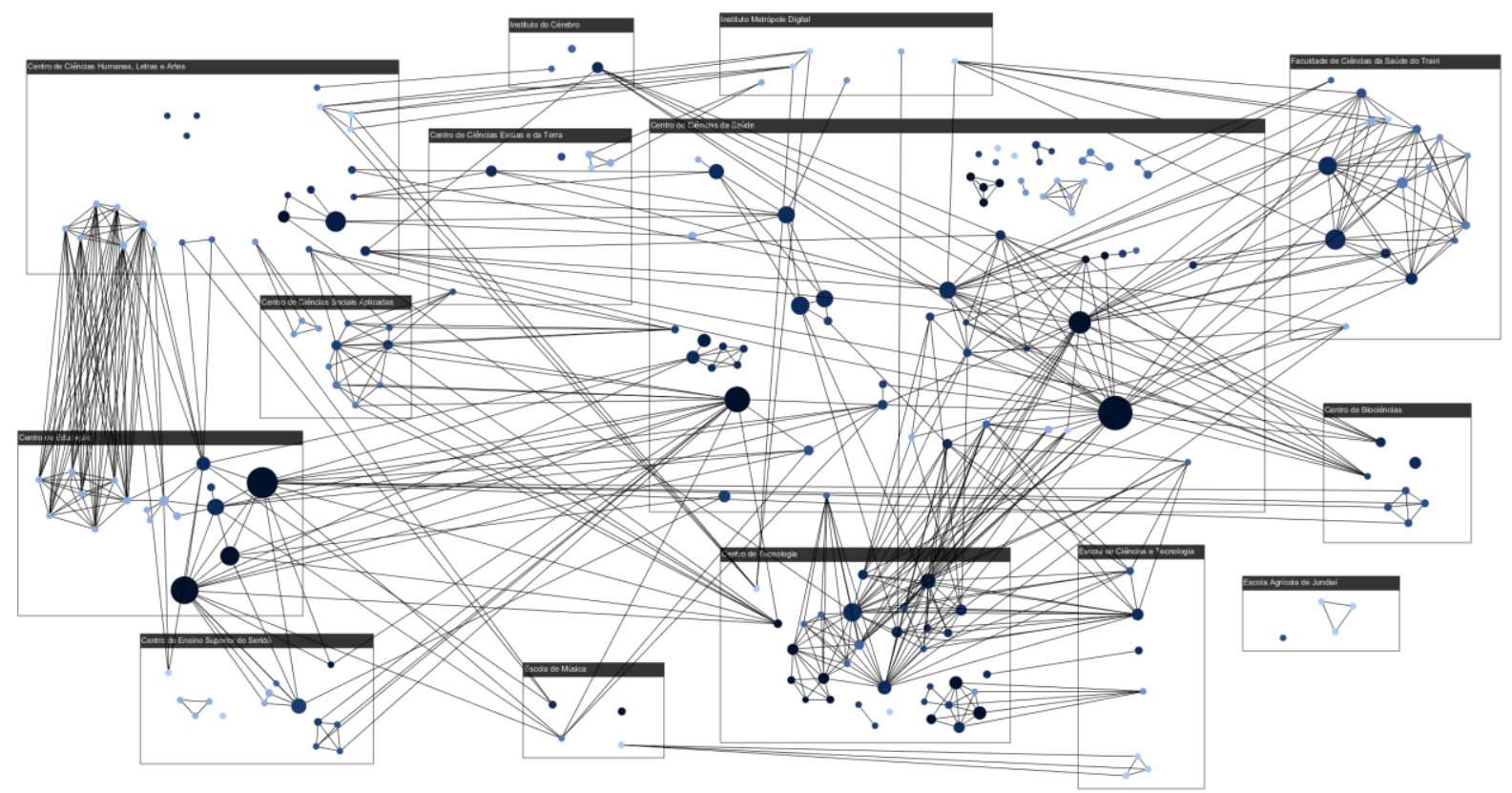

Fonte: Portal de Dados Abertos da UFRN e SIGAA 


\section{Ism Ẽthapga}

ISSN: 1984-6444 | http://dx.doi.org/10.5902/1984644432632

As muitas linhas indicam interações dentro dos centros e entre centros, quando cruzam os retângulos. Poucos docentes pesquisaram sozinhos. Alguns realizaram pesquisa em grupos pequenos e isolados. Porém, a maioria deles colaborou significativamente, conforme ilustrado pelos grupos formados. Apenas a Escola Agrícola de Jundiaí trabalhou de forma isolada. Vale notar as colaborações entre centros da capital e do interior, como aquelas entre o Centro de Ensino Superior do Seridó, no interior, e o Centro de Educação, o Centro de Ciências da Saúde e o Centro de Ciências Humanas, Letras e Artes, na capital; e entre a Faculdade de Ciências da Saúde do Trairi, no interior, e o Centro de Ciências da Saúde, o Centro de Tecnologia e o Instituto Metrópole Digital, na capital. Como em extensão, essa colaboração entre centros evidencia o forte caráter interdisciplinar nas pesquisas relacionadas com deficiência na UFRN.

\section{Discussão dos Resultados}

Quase todos os centros na capital e no interior estão envolvidos com a temática deficiência. $O$ ano de ingresso e, consequentemente, a idade dos docentes não dificultou sua participação em pesquisa e em extensão. Docentes antigos e novos participaram, apesar de uma quantidade bem maior de antigos. Talvez pelos antigos estarem melhor estabelecidos na carreira. A quantidade de projetos e de extensão variou muito entre centros, porém foi regular. A distribuição foi ligeiramente pior em extensão do que em pesquisa.

Deficiências em geral e, especificamente, deficiência visual, auditiva e intelectual foram mais abordadas em projetos de extensão do que em pesquisa. Deficiência motora e autismo foram mais abordadas em projetos de pesquisa do que em extensão. Dificuldades de aprendizagem recebeu o mesmo número de projetos em ambos os casos. A convivência com discentes com deficiências não influenciou a quantidade de projetos de pesquisa e de extensão realizados. Por exemplo, a universidade teve mais discentes com dificuldades de aprendizagem e esta foi a deficiência que menos recebeu atenção em pesquisa e extensão. Os centros que atuam na área de educação na capital e no interior não realizaram projetos de 


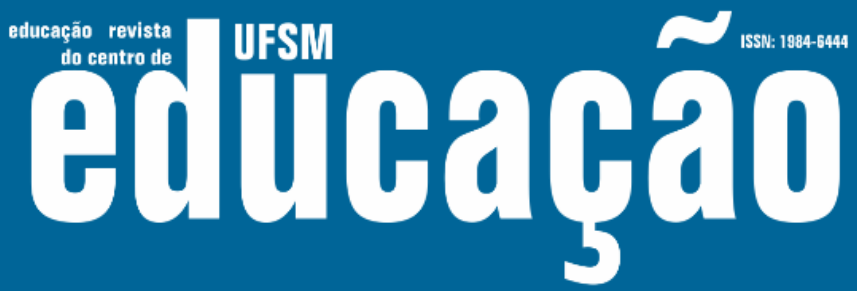

ISSN: 1984-6444 | http://dx.doi.org/10.5902/1984644432632

pesquisa sobre dificuldades de aprendizagem, apesar terem uma participação muito baixa em extensão relacionada com este público. A deficiência auditiva recebeu maior atenção em extensão, provavelmente por influência dos cursos de Letras - Língua Portuguesa e Libras e de Fonoaudiologia. A deficiência motora recebeu maior atenção em pesquisa, principalmente na área de saúde e tecnologia. Em geral, as deficiências foram abordadas em vários centros, e um centro abordou várias deficiências. Houve pouca concentração centro-deficiência.

Os projetos de extensão e de pesquisa abordaram uma grande variedade de temas, agrupados por educação, prestação de serviços, tecnologias, cidadania e pessoa com deficiência. Este último grupo foi abordado apenas em pesquisas. Mesmo em educação, os temas foram além do tradicional, incluindo a formação de prestadores de serviço e das pessoas que convivem com deficientes. Houve boa distribuição dos temas em extensão e em pesquisa pelos centros da capital e do interior, sem concentração expressiva. Esses são bons indícios de que a universidade considera a temática deficiência de uma forma mais ampla, objetivando a inclusão no ensino superior e na sociedade.

A identificação da atuação anterior da universidade sobre deficiências e temas pode ser utilizada para estimular sua atuação futura. Por exemplo, a UFRN ainda não realizou extensão e pesquisa para desenvolver tecnologias de apoio às dificuldades de aprendizagem. Ela também abordou muito pouco a questão do trabalho de pessoas com deficiência em projetos de extensão e pesquisa. Editais específicos poderiam oferecer estímulos nessas direções. Outro estímulo relevante seria promover a consolidação e divulgação de resultados de extensão e pesquisa sobre as deficiências e temas abordados na universidade. A análise desse panorama de atuação da instituição configura-se como importante instrumento de gestão.

A característica mais importante dessa experiência da UFRN foi a colaboração entre docentes em extensão e pesquisa relacionados com o tema deficiência. Quando um docente busca colaborar com outros, ainda que inconscientemente, ele busca superar suas limitações pessoais através de um trabalho coletivo. A colaboração é um forte indício de que lidar com pessoas com deficiência é um problema grande e complexo demais para sua limitação de esforço ou de conhecimentos e práticas de 


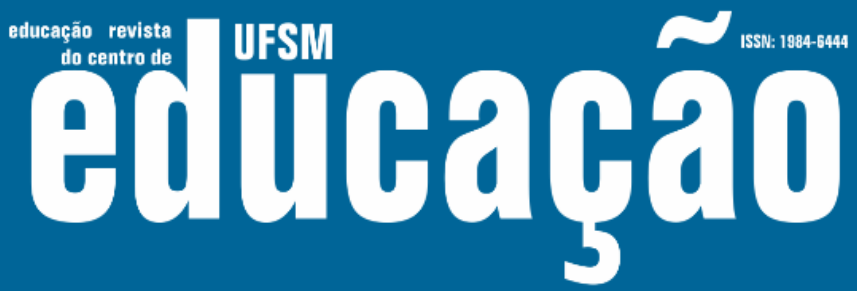

ISSN: 1984-6444 | http://dx.doi.org/10.5902/1984644432632

sua área de atuação. As barreiras atitudinais começaram a cair quando alguns docentes perceberam que possuem limitações do mesmo modo que as pessoas com deficiência também possuem as suas. As naturais limitações humanas, que outrora excluíram, passaram a estimular ações de inclusão através de projetos de extensão e pesquisa.

Os diálogos e experiências proporcionados pela colaboração entre docentes foram um importante fator de propagação do movimento de inclusão de pessoas com deficiência na universidade. Como a cultura é uma construção social, esses diálogos e experiências têm o poder de mudar a cultura dos docentes em termos de crenças e práticas de trabalho, para remover as barreiras atitudinais em relação às pessoas com deficiência.

Quando um docente percebe que precisa de ajuda para conseguir alcançar algum objetivo de extensão ou de pesquisa, ele tende a procurar ajuda de quem está mais próximo dele, dando origem a colaborações dentro dos centros ou entre centros com atuações na mesma área. Um próximo passo costuma ser buscar ajuda com docentes de outras áreas, dando origem a colaborações interdisciplinares entre centros. A interdisciplinaridade é outra característica importante nesse movimento de inclusão. Uma interação maior entre os docentes com formações e vivências diferentes tende a estimular atuações com uma maior diversidade de deficiências e de temas. Nesse processo de diálogo e colaboração entre docentes, o movimento de inclusão tem sido propagado pelos centros, áreas, deficiências e temas na universidade.

Muitos docentes que se envolveram em projetos no início do período estudado possuem uma boa quantidade de colaborações dentro e fora dos seus centros. Quase todos os centros possuem mais de um grupo de docentes trabalhando em projetos de pesquisa e extensão relacionados ao tema deficiência. Mesmo que determinados grupos de docentes dentro de um centro não colaborem diretamente em projetos, o fato de ter um colega próximo que trabalha com o tema deficiência também deve ter estimulado outros docentes a se envolverem em projetos deste tipo. Muitos projetos de pesquisa e de extensão analisados foram interdisciplinares, envolvendo, por exemplo, docentes de educação-saúde, tecnologia-educação e arte-educação. 


\section{T usm Eulloabुa}

ISSN: 1984-6444 | http://dx.doi.org/10.5902/1984644432632

\section{Considerações Finais}

Este trabalho investigou a atuação dos docentes da UFRN em pesquisa e extensão relacionadas com o tema deficiência dez anos antes das cotas (2008-2017). Buscou-se identificar experiências que podem contribuir para remover as barreiras atitudinais dos docentes. Como pesquisa e extensão costumam ser atividades mais diversificadas, dinâmicas e flexíveis do que a prática pedagógica cotidiana, as atividades docentes extraclasse tendem a ser um caminho interessante para enfrentar as barreiras atitudinais docentes. Depois de rever suas crenças e compreender melhor a temática deficiência, o docente terá melhores condições de aprimorar suas práticas pedagógicas para a inclusão.

As leis e políticas de inclusão no ensino superior possuem papel importante como norteadoras e indutoras, mas ainda precisam de estratégias para serem colocadas em prática. A colaboração e a interdisciplinaridade entre professores têm potencial para propagar e diversificar o movimento de inclusão de pessoas com deficiência no ensino superior, em particular contribuindo para remoção das barreiras atitudinais dos docentes.

\section{Referências}

AINSCOW, M. Necesidades especiales en el aula. Guía para la formación del profesorado. Paris: UNESCO; Madrid: NARCEA, 1995.

ALBINO, I.B. Acesso e permanência na universidade federal do rio grande do Norte sob o ponto de vista do docente e do estudante com deficiência Natal-RN. Dissertação (Mestrado em Educação) - Universidade Federal do Rio Grande do Norte, Natal, 2010.

ALENCAR, P.M.M. Acessibilidade no ensino superior: o caso da UFJF. Dissertação de Mestrado em Gestão e Avaliação em Educação Pública Universidade Federal de Juiz de Fora, Juiz de Fora, 2013.

BRASIL. Presidência da República. Decreto Legislativo no 186, de 9 de julho de 2008. Disponível em: <http://www.planalto.gov.br/ccivil_03/Congresso/DLG/DLG-1862008.htm>. Acesso em maio de 2018.

BRASIL. Presidência da República. Decreto no 7.611, de 17 de novembro de 2011. Disponível em: <http://www.planalto.gov.br/ccivil_03/_ato2011-2014/2011/decreto/ d7611.htm >. Acesso em maio de 2018. 


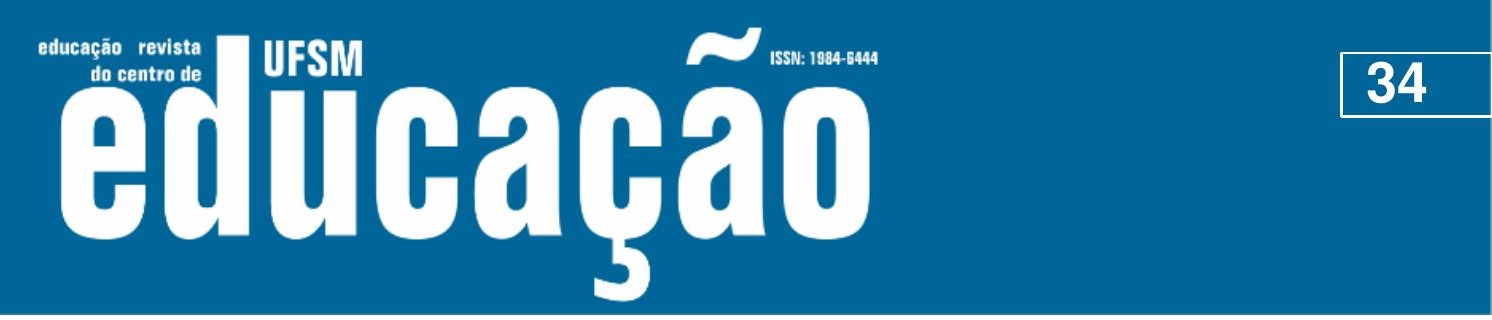

ISSN: 1984-6444 | http://dx.doi.org/10.5902/1984644432632

BRASIL. Presidência da República. Lei no 13.146, de 6 de julho de 2015. Disponível em: <http://www.planalto.gov.br/ccivil_03/_ato2015-2018/2015/lei//13146.htm>. Acesso em maio de 2018.

BRASIL. Presidência da República. Lei no 13.409, de 28 de dezembro de 2016. Disponível em: <http://www.planalto.gov.br/ccivil_03/_Ato2015-2018/2016/Lei/ L13409.htm>. Acesso em maio de 2018.

CASTRO, S.F.; ALMEIDA, M.A. Ingresso e permanência de alunos com deficiência em universidades públicas brasileiras. Rev. bras. educ. espec., Jun 2014, vol.20, no.2, p.179-194. ISSN 1413-6538.

CHAHINI, T.H.C. Atitudes sociais e opiniões de professores e alunos da Universidade Federal do Maranhão em relação à inclusão de alunos com deficiência na educação superior. Tese de Doutorado em Educação - Universidade Estadual Paulista, Faculdade de Filosofia e Ciências, 2010.

CIANTELLI, A.P.C.; LEITE, L.P. Ações Exercidas pelos Núcleos de Acessibilidade nas Universidades Federais Brasileiras. Rev. bras. educ. espec., Set 2016, vol.22, no.3, p.413-428. ISSN 1413-6538.

DUARTE, E.R. et al. Estudo de caso sobre a inclusão de alunos com deficiência no Ensino Superior. Rev. bras. educ. espec. 2013, vol.19, n.2, pp.289-300.

FERREIRA, E.L.L.S. A política de inclusão de estudantes cegos na educação superior na UFRN: do acesso à permanência. 2016. 138f. Dissertação (Mestrado em Serviço Social) - Centro de Ciências Sociais Aplicadas, Universidade Federal do Rio Grande do Norte, Natal, 2016.

GIL, A.C. Métodos e técnicas de pesquisa social. 6. ed. - São Paulo: Atlas, 2008.

MAGALHÂES, R.C.B.P. Currículo e inclusão de alunos com deficiência no ensino superior: reflexões sobre a docência universitária. In: Francisco Ricardo Lins Vieira de Melo. (Org.). Inclusão no ensino superior: docência e necessidades educacionais especiais. 1ed. Natal: ED. UFRN, 2013, v. 1, p. 47-55.

MANTOAN, M.T.E.; BARANAUSKAS, M.C.C. Atores da inclusão na universidade: formação e compromisso. Campinas, SP: UNICAMP, 2009.

MARTINS, L.M.S.M. Práticas e formação docente na UFRN com vistas à inclusão de estudantes cegos. 2016. 154f. Dissertação (Mestrado em Educação) - Centro de Educação, Universidade Federal do Rio Grande do Norte, Natal, 2016.

MELO, F.R.L.V.; MEDEIROS, R. Inclusão de alunos com deficiência no ensino superior: ações no contexto da Universidade Federal do Rio Grande do Norte. Anais do IV Congresso Brasileiro Multidisciplinar de Educação Especial, 2007. 


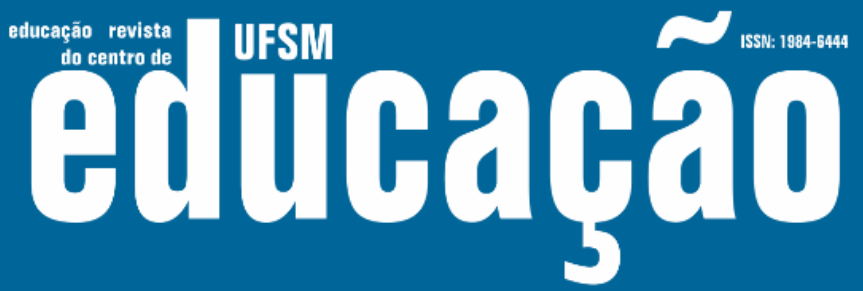

ISSN: 1984-6444 | http://dx.doi.org/10.5902/1984644432632

SALTON, B.P.; AGNOL, A.D.; TURCATTI, A. Manual de acessibilidade em documentos digitais. Bento Gonçalves, RS: Instituto Federal de Educação, Ciência e Tecnologia do Rio Grande do Sul, 2017.

SARAIVA, L.L.O. Núcleos de acessibilidade e o atendimento a alunos com necessidades educacionais especiais nas universidades federais do nordeste brasileiro. Dissertação (Mestrado em Educação) - Centro de Educação, Universidade Federal do Rio Grande do Norte, Natal, 2015.

SEVERINO, M.P.S.R.S. Avaliação do processo de implementação do Programa Incluir na Universidade Federal do Rio Grande do Norte (2012-2014). Tese (Doutorado em Ciências Sociais) - Centro de Ciências Humanas, Letras e Artes, Universidade Federal do Rio Grande do Norte, Natal, 2017.

\section{Correspondência}

Bruno Santana da Silva - Professor doutor da Universidade Federal do Rio Grande do Norte (UFRN), Natal, Rio Grande do Norte, Brasil.

Adja Ferreira de Andrade - Professora doutora da Universidade Federal do Rio Grande do Norte (UFRN), Natal, Rio Grande do Norte, Brasil.

Universidade Federal do Rio Grande do Norte, Instituto Metrópole Digital. Campus Universitário - Lagoa Nova, CEP: 59078-970. Natal, Rio Grande do Norte, Brasil.

E-mail: bruno@imd.ufrn.br - adja@imd.ufrn.br

\section{(C) $(1) \Theta$}

This work is licensed under a Creative Commons Attribution-NonCommercial 4.0 International (CC BY-NC 4.0) 